Article

\title{
Asymmetrical Pulse-Width Modulation Strategy for Current-Fed Dual Active Bridge Bidirectional Isolated Converter Applied to Energy Storage Systems
}

\author{
Edivan Laercio Carvalho ${ }^{\circledR}$, Luiz Henrique Meneghetti, Emerson Giovani Carati ${ }^{\circledR}$,

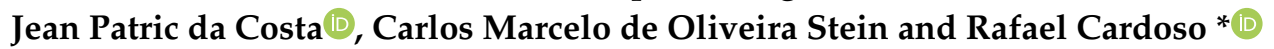 \\ Department of Electrical Engineering, Graduate Program in Electrical Engineering, Universidade Tecnológica \\ Federal do Paraná-UTFPR, Pato Branco-PR 85503-390, Brazil; e.carvalho@ieee.org (E.L.C.); \\ meneghetti@alunos.utfpr.edu.br (L.H.M.); emerson@utfpr.edu.br (E.G.C.); jpcosta@utfpr.edu.br (J.P.d.C.); \\ cmstein@utfpr.edu.br (C.M.d.O.S.) \\ * Correspondence: rcardoso@utfpr.edu.br
}

Received: 17 March 2020; Accepted: 19 June 2020; Published: 5 July 2020

\begin{abstract}
This paper proposes an asymmetrical pulse-width modulation (PWM) strategy for current-fed dual-active bridge (CFDAB) converters applied to energy storage systems (ESS). The ESS application considers low-voltage and high-capacity batteries, for low-power applications, such as data centers, residential photovoltaic systems (PV), and uninterruptable power supplies (UPS). The proposed modulation permits the use of an isolation transformer with negligible leakage inductance and, therefore, avoids the use of auxiliary circuits such as snubbers, active-clamp, or resonant cells. Hence, the converter implementation is simplified. The modulation also benefits the design of the control system because the converter can be modeled and controlled using simple strategies. A straightforward, large-signal model for the battery charge mode, which is valid over all the operation range of the converter, is obtained. Also, the converter operates with a fixed dc bus voltage on both charge and discharge modes. These characteristics represent a significant advantage when the CFDAB with PWM modulation is compared with phase-shifted or frequency modulations, commonly applied in these converters.
\end{abstract}

Keywords: bidirectional converters; current-fed dual-active bridge; energy storage systems; PWM control

\section{Introduction}

Renewable generation sources, such as photovoltaic (PV), have been widely used in microgrids and nanogrids. However, such systems have an intermittent generation and, therefore, they are not able to provide constant or dispatchable power generation [1-3]. The ability to provide controllable output power is important to increase the power system stability and to allow better operation planning [1-4]. This task can be shared at different generation levels, including microgrids, high-power plants, and low-power systems, as nanogrids and residential and commercial applications [1].

An alternative to providing a generation with constant and controllable output power is the incorporation of energy storage systems (ESS) associated with the PV generation, in different application levels. Due to the high costs related to the construction of high-voltage devices, the insertion of batteries with low voltage and high capacity is of great interest, mainly in small-size systems [2,5-8]. Besides, the use of reduced-voltage ESS provides more safety for the users, concerning electrical shocks and, therefore, they are indicated for low-power applications, as residential loads and hybrid PV inverters [2]. 
As an example, in the PV generation, due to the low-voltage levels commonly found in panels and strings, it is necessary to use converters with high-voltage gain to allow the connection of primary power sources to the dc buses used on the interface inverters of the distributed generation with the ac grid $[7,8]$. This also occurs in bidirectional converters when connecting the low-voltage ESS with dc buses. However, during battery charging, the converter should act as a voltage reducer. Thus, interest arises in the development of bidirectional dc-dc converters with high-voltage gain [9-14].

Non-isolated converters are a possibility $[15,16]$. However, due to performance issues and mainly battery bank safety, the use of isolated converters is preferable, which, in addition to providing high voltage-gains, ensure galvanic insolation to the batteries [9-14]. The isolated approach is found in [8-13], where the use of the conventional Dual-Active bridge converter (DAB) is proposed. This configuration is illustrated in Figure 1, where two active bridges, represented by the full-bridge converters, $A$ and $B$, are used to provide a bidirectional power flow between dc bus $\left(v_{1}\right)$ and batteries $\left(v_{2}\right)$.

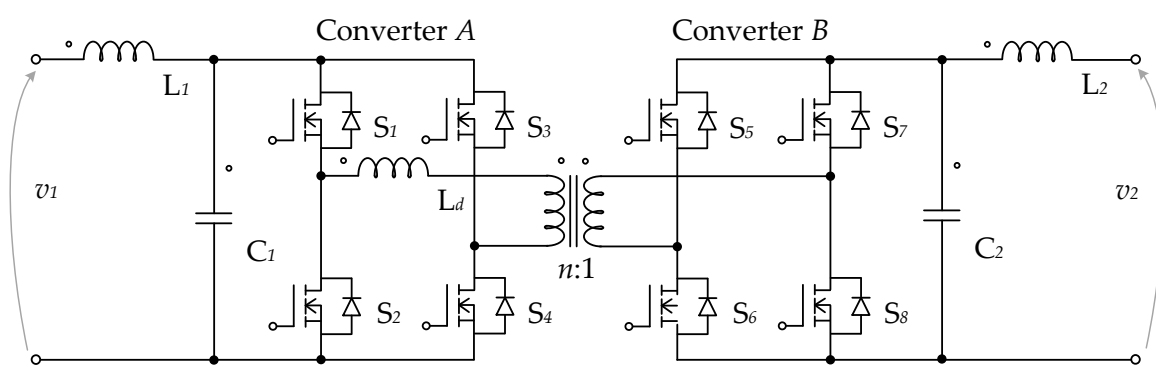

Figure 1. Conventional dual-active bridge converter, commonly found on bidirectional applications.

In the conventional DAB configuration, the converter and its modulation are proposed to use the high-frequency (HF) transformer as an energy-storage element. As a consequence, some resulting aspects should be mentioned: (1) The transformer must have high leakage inductance, therefore, there is an increase in volume as well in magnetic losses; (2) related to the modulations' aspects, this characteristic limits the converter operation, due to the frequency modulation on resonant circuits $[4,9,17]$, or phase-shift (PS) modulations [11,13]. Thus, in the conventional DAB configuration, some degrees of freedom are lost regarding the choice of the modulation and, consequently, the control design — which is based on a linearized model and small-signals' approaches, which are only valid in a limited range of operation $[4,9,11,13,17]$.

Related to steady-state analysis, the DAB converter has a high-current ripple in the output capacitors and consequently is commonly implemented with electrolytic capacitors $[7,8,14]$. Due to this, many systems increase the allowable capacitors' voltage ripple or use multiple capacitors in parallel to increase the processing power [9-14].

Also, a disadvantage of the conventional DAB configuration, there are voltage-fed converters on both sides of the system. Thus, depending on the modulation, the increase in voltage ratio is only up to the isolation transformer, which limits the dc bus regulation when considering the charging and discharging processes [9-13]. In [9,13], this characteristic limits the converter range of voltage gain. Therefore, the dc bus operates with different voltage levels when considering the two operating modes of the system.

Due to issues concerning the protection schemes and the modulating index of other possible converters connected to the dc bus, it is desirable to maintain its operation voltage constant in both system operation modes. To accomplish this, during the batteries charging process, the dc bus voltage must be reduced at the transformer terminals and, in the batteries discharging, its voltage must be increased. This avoids the use of a transformer with a variable turns' ratio to keep the dc bus voltage constant [14]. Furthermore, the insertion of $\mathrm{L}_{1}$ and $\mathrm{L}_{2}$ filters, depicted in Figure 1, is necessary to limit current ripples in the dc bus and, especially, in the batteries $[13,14]$.

Concerning the transient analysis, the generalized average model of the DAB converter is presented in $[18,19]$. In this approach, through the Fourier series, it is possible to include in the model 
terms associated with high-frequency ripples. These terms are related to the energy stored in the transformer. In $[4,9,17]$, the converter was modeled and controlled by frequency strategies. In both cases, small-signals' models were used and, therefore, the control system was only valid on a restricted operation range.

Some of the limitations cited above can be overcome by choosing an asymmetrical converter, as opposed to the DAB in its traditional configuration. This paper proposes the application of an asymmetrical converter, which is voltage fed on the high-voltage side and current fed on the low-voltage side. This converter is commonly called current-fed dual-active bridge (CFDAB) [11].

In the CFDAB, depicted in Figure 2, in which the sensors, semiconductors, and filters are shown, the converter is current fed on the low-voltage side. This naturally allows reducing the current ripple in the output capacitor, due to the addition of the current filter $\left(\mathrm{L}_{2}\right)$. Related to the insulation transformer, the CFDAB is not necessarily dependent on the leakage inductances, which makes possible the construction of transformer with high-relative-magnetic permeability materials, as the nanocrystalline cores.

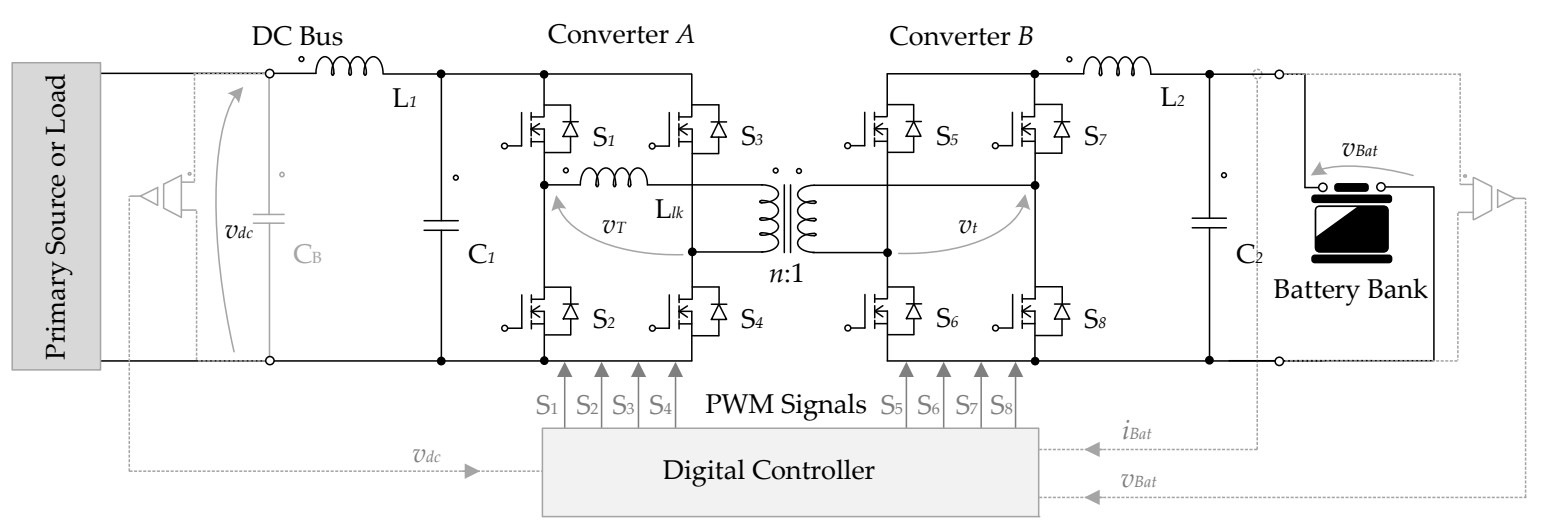

Figure 2. The power circuit diagram, instrumentation, and control of the proposed current-fed dual active bridge (CFDAB) converter.

A possible advantage of the DAB converter is robustness since the CFDAB naturally suffers from resonances and overvoltage problems due to the parasitic elements of HF transformer. These are recurrent problems in isolated converters, especially in bidirectional applications, which imply more voltage stress, power losses, and electromagnetic interference. It may reduce efficiency and also compromise the safe operation of the semiconductors $[11,12,14,20]$.

Reference [11] reduces the overvoltage problems by using a specific modulation, the addition of two auxiliary inductors and a voltage-clamp cell. In [12,20], auxiliary circuits were proposed to reduce the overvoltage problems in CFDAB converters. In both cases, the modulations used were simpler than the modulation presented in [11]. However, the converter efficiency was compromised, and an active semiconductor was added in the circuit. In $[4,9,17]$, resonant cells were applied. This allowed the soft-switching operation. However, the converters were frequency modulated, which naturally limited the control system to a limited operating range.

Even though the CFDAB is a known converter topology, the current literature still lacks a clear and comprehensive definition of the issues of modulation and control of bidirectional converters. Evidencing the lack of an appropriate modulation to the operation and control of the CFDAB converter, this paper proposes the asymmetrical PWM modulation strategies that allow the use of a transformer with reduced leakage inductance and high-relative-magnetic permeability cores. Besides, the transformers used in $\mathrm{DAB}$ converters present higher volume and magnetic losses due to the higher leakage inductances. Also, it is necessary to mention that the overvoltage problems in current-fed isolated converters are also related to the high value of the leakage inductance of the insulation transformer. The result is that it is possible to operate the CFDAB converter without auxiliary circuits as resonant cells, snubbers, or active-clamp cells if the leakage inductance is reduced. This is significant 
because, naturally, current-fed isolated topologies suffer from resonances and overvoltage problems in the transformer and the semiconductors due to the transformer leakage inductance [7,20-22].

Besides, in $[11,12,20]$ the CFDAB converter was controlled with phase-shift modulation. In the PS approach, converter modeling is complex because the models are analyzed through the Fourier series. In this paper, simpler strategies were used to design the control system, based on PWM control. In $[18,19]$, the whole document was developed to obtain a linearized model, to represent the DAB converter. On the other hand, by applying the asymmetrical configuration and PWM strategy proposed in this paper, it was possible to obtain simplified models to the CFDAB converter.

Considering the asymmetrical modulations' strategies as the main paper contribution applied to a CFDAB converter leads to clear advantages when compared to previously cited papers, including: (1) Reduced stress on the semiconductors without the use of auxiliary circuits or resonant cells $[4,9,12,20]$; (2) transformer with reduced volume, due to the low leakage inductance; (3) wide voltage gain $[9,13]$; (4) use of the same voltage level in the dc bus for both operation modes (batteries charge/discharge) $[9,13]$; (5) control by PWM strategies that are simpler than PS and frequency modulations [4,9,17-19]; and (6) linear large-signal model for the batteries' charge operation mode $[4,9,17-19]$.

\section{Steady-State Analysis}

The proposal presented in this paper dealt with the converter operation modes independently, requiring individual analysis for each operation mode. For the battery bank charge, it was possible to relate the voltage of the dc bus and batteries through a large-signals' model, directly dependent on the converter duty-cycle $(D)$.

In cases of absence of the primary source (failure in the dc-dc system of PV generation or the absence of solar irradiation, for example), the converter acts as a step-up converter. For this operation mode, the proposed modulation has the aim of reducing the differences of current between the transformer and the inductive filter $\left(\mathrm{L}_{2}\right)$, a common problem in current-fed converters. For both operation modes, PWM modulations to the system control are adopted, which represents a significant advantage to resonant converters and PS modulation.

To expose in detail the converter implementation, the main power stages and equations involved in the converter sizing will be presented in the following subsections. To simplify the analysis that will follow, the following hypotheses were considered: (1) The capacitor $C_{B}$ referring to the dc bus was high enough to be represented by an ideal voltage source- $v_{d c}$, (2) the voltage on the capacitor $C_{1}$ was constant and equal to $v_{d c}$, (3) the transformer's magnetizing inductance was large enough to be neglected, (4) the semiconductors were considered ideal, and (5) the low ripple levels of current in both operation modes resulted in a continuous conduction mode.

\subsection{Analysis of the Converter on the Step-Down Mode}

For the charging process of the battery bank, the converter operates to reduce the voltage of the dc bus. To perform the converter analysis, Figure 3 shows the equivalent circuit of each power stage.

Stage 1 (Figure 3a), $t_{0}-t_{1}$ : For the positive semicycle, the semiconductors $S_{1}$ and $S_{4}$ are put in conduction, while $S_{2}$ and $S_{3}$ remain blocked. The energy from the input source is directly transferred to the battery through a positive voltage on the transformer and by the direct polarization of the $S_{6}$ and $S_{7}$ diodes. As a result: $v_{L 2}=v_{d d} / n-v_{B a t}$ and $i_{C 2}=i_{L 2}-i_{B a t}$.

Stage 2 (Figure $3 b), t_{1}-t_{2}$ : In a second moment, for the power flow between the battery and $d c$ bus to be interrupted, $S_{1}$ is blocked. However, $S_{4}$ must be maintained in conduction so that $S_{2}$ enters in conduction with zero voltage, reducing the switching losses of the converter and ensuring a path to the transformer surplus current. Concerning the circuit analysis, there are: $v_{L 2}=-v_{B a t}$ and $i_{C 2}=i_{L 2}-i_{B a t}$.

Stage 3 (Figure $3 c$ ), $t_{2}-t_{3}$ : During the negative semicycle, two similar stages occur. Therefore, for stage $3, S_{2}$ and $S_{3}$ are put in conduction while $S_{1}$ and $S_{4}$ are blocked. The voltage $v_{T}$ becomes negative, which, when rectified by the $S_{5}$ and $S_{8}$ diodes, results in: $v_{L 2}=v_{d d} n-v_{B a t}$ and $i_{C 2}=i_{L 2}-i_{B a t}$. 
Stage 4 (Figure $3 \mathrm{~d}), t_{2}-T$ : In the last operation stage, the semiconductor $\mathrm{S}_{2}$ remains in conduction, while $S_{3}$ is blocked resulting in zero voltage in the transformer-similar to stage 2 . Therefore, once again: $v_{L 2}=-v_{B a t}$ and $i_{C 2}=i_{L 2}-i_{B a t}$.

To avoid saturation problems of the transformer, the intervals $t_{0}-t_{1}$ and $t_{2}-t_{3}$ must be equal. The duty-cycle is defined by the ratio $D=2 t_{o n} / T$, where $T$ is the switching period and $t_{o n}=t_{0}-t_{1}=t_{2}-t_{3}$, since these time intervals represent the power stages of the energy transfer.

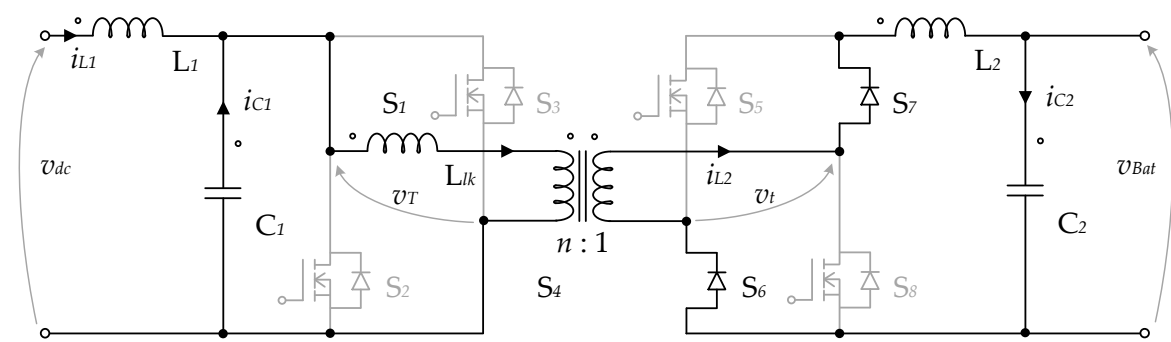

(a)

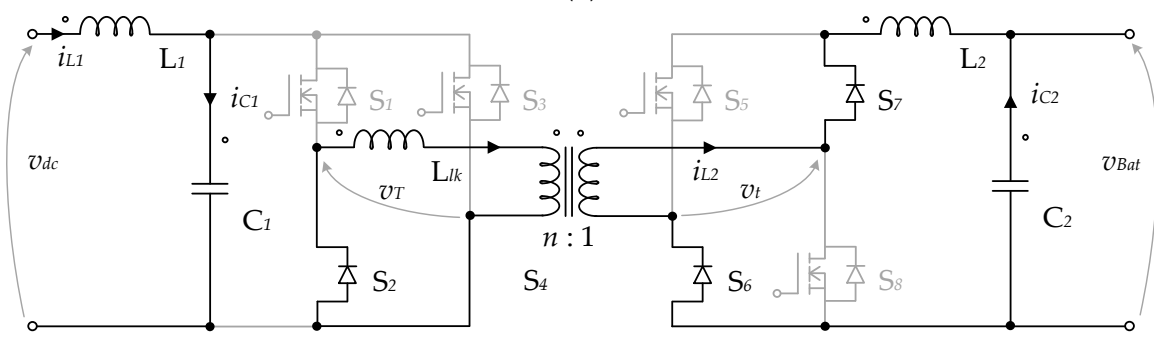

(b)

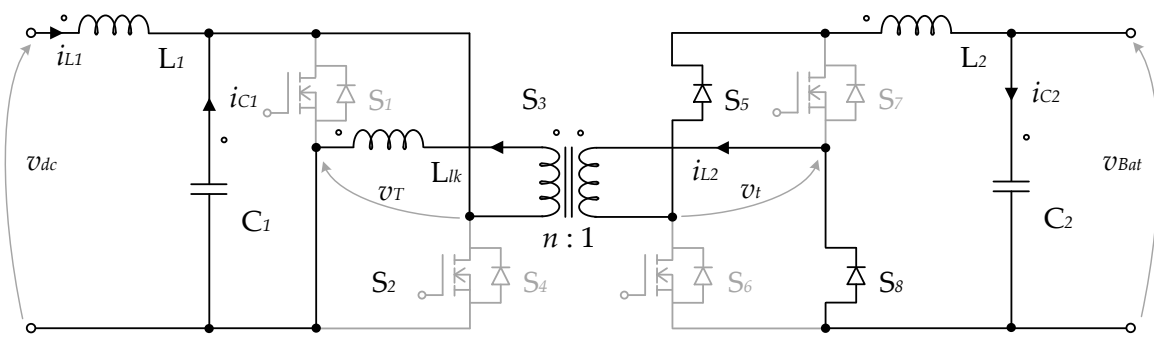

(c)

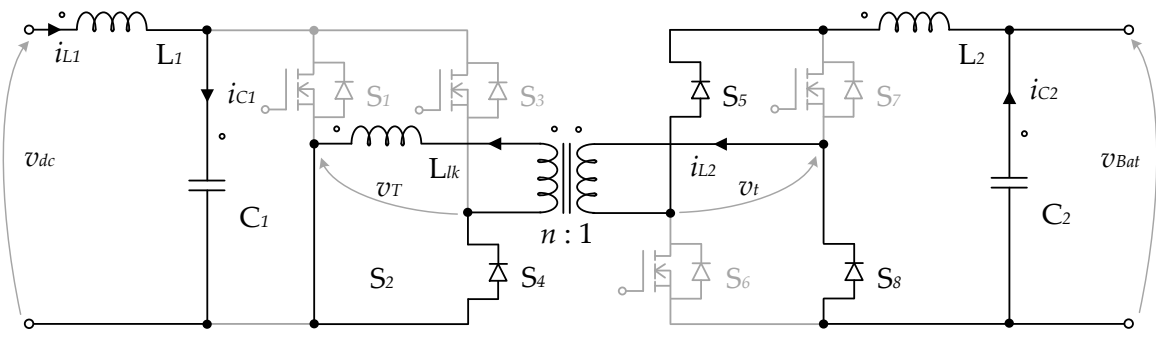

(d)

Figure 3. Equivalent circuits of the converter power stages operating in step-down mode, during battery charging: (a) Stage 1, (b) Stage 2, (c) Stage 3, (d) Stage 4.

To define the static-gain equation, it is considered that the $\mathrm{L}_{2}$ voltage is zero during the period $T$. In this way, it is necessary to weigh the equations referring to $v_{L 2}$ according to the time in which they occur.

$$
\frac{v_{B a t}}{v_{d c}}=\frac{D}{n}
$$

From the analysis of Equation (1), the direct dependence of the output voltage $\left(v_{B a t}\right)$ by the variable $D$ is evident. This interpretation is of fundamental importance for the development of the control 
design for the batteries' charge mode, since it allows the representation of the converter directly using a large-signal model.

To define the value of $\mathrm{L}_{2}$, the methodology presented in [6] was followed, considering that during Stages 2 and 4 the voltage across $L_{2}$ was equal to $v_{B a t}$. These stages occur for a time $(1-D) /(2 f)$, which defines $\mathrm{L}_{2}$ through:

$$
L_{2}=\frac{v_{L 2} \Delta t}{\Delta i_{L 2}}=\frac{v_{B a t}(1-D)}{\Delta i_{L 2} 2 f}=\frac{v_{d c}\left(D-D^{2}\right)}{n \Delta i_{L 2} 2 f}
$$

in which $f$ is equal to $1 / T$, being the converter-switching frequency, and $\Delta i_{L 2}$ is the current ripple, defined according to the application interests.

For the capacitor $\mathrm{C}_{2}$, it is assumed that it is charged during a period equal to $\mathrm{T} / 4$, when its current is positive and equal to $\Delta i_{L} / 2$. In which $\Delta Q$ is the capacitor charge variation and is given by:

$$
\Delta Q=\left(\frac{1}{2}\right)\left(\frac{T}{4}\right)\left(\frac{\Delta i_{L}}{2}\right)=\frac{T \Delta i_{L}}{16}
$$

and, considering the relation $\Delta Q=C \Delta v_{C}$, where $\Delta v_{C}$ is the capacitor voltage variation, the value of $C_{2}$ is obtained by rewriting Equation (3) in function of $C_{2}$ and replacing $\Delta i_{L}$ from Equation (2) to Equation (3), so:

$$
C_{2}=\frac{i_{C 2} \Delta t}{\Delta v_{C 2}}=\frac{v_{B a t}(1-D)}{32 \Delta v_{C 2} L_{2} f^{2}}=\frac{v_{d c}\left(D-D^{2}\right)}{32 n \Delta v_{C 2} L_{2} f^{2}}
$$

\subsection{Analysis of the Converter on the Step-Up Mode}

In the battery discharge mode, the converter acts as a step-up converter to regulate the dc bus voltage. In this operation mode, the converter $B$ operates as an inverter and converter $A$ as a rectifier.

For the drive of the converters, different modulation strategies are found in the literature, as presented in $[6,11]$. In both cases, there are problems related to the semiconductors' overvoltage, due to current differences of $\mathrm{L}_{2}$ and the intrinsic inductances of the transformer. This characteristic is common in current-fed converters and it justifies the applications of active-clamp circuits or passive snubbers $[11,20,22]$. In this paper, the modulation strategy was proposed to attenuate this problem. The modulation proposed was implemented according to the power stages shown in Figure 4, similar to the PWM modulation applied to the step-down mode.

Stage 1 (Figure $4 a), t_{0}-t_{1}$ : Initially, $S_{6}$ and $S_{7}$ must be in conduction and $S_{5}$ and $S_{8}$ are blocked. For the magnetization of the inductor $\mathrm{L}_{2}$, it is proposed that $\mathrm{S}_{2}$ be turned on, acting in conduction to ensure that the transformer current is similar to $i_{L 2}$. This argument is necessary to avoid problems related to overvoltage during the blocking of semiconductors. In this stage $v_{L 2}=v_{B a t}$ and $i_{C 1}=-i_{L 1}$.

Stage 2 (Figure $4 b$ ), $t_{1}-t_{2}$ : In a second moment, the energy stored in $L_{2}$ is transferred to the dc bus, with $\mathrm{S}_{2}$ blocked, resulting in $v_{L 2}=v_{B a t}-v_{d d} n$. In this case, the capacitor is charged with mboxemphi $\mathrm{C}_{1}=\mathrm{i}_{\mathrm{L} 2} / \mathrm{n}-i_{\mathrm{L} 1}$.

Stage 3 (Figure $4 c), t_{2}-t_{3}$ : In the negative semicycle, $S_{5}$ and $S_{8}$ must be in conduction. Similarly to Stages 1 and 2, the inductor $L_{2}$ is magnetized through $S_{4}$, so that the transformer current is similar to $i_{L 2}$. At this moment, the transformer current becomes negative, while $v_{L 2}=v_{B a t}$ and $i_{C 1}=-i_{L 1}$.

Stage 4 (Figure $4 \mathrm{~d}$ ), $t_{2}-T$ : In the last power stage, so that the $\mathrm{L}_{2}$ stored energy is transferred back to dc bus, the semiconductor $S_{4}$ must be blocked, returning to $v_{L 2}=v_{B a t}-v_{d d} / n$ and $i_{C 1}=i_{L 2} / n-i_{L 1}$.

To define the static-gain and filters' equations, it is again assumed that the average voltage across the $\mathrm{L}_{2}$ inductor is zero during a period $T$, therefore,

$$
\frac{v_{d c}}{v_{B a t}}=\frac{n}{1-D}
$$


To size the capacitor $C_{1}$, it is assumed that during Stages 2 or 4 , the $i_{C 1}$ current is equal to $i_{L 1}$, during a period proportional to $D /(2 f)$. In this way, $C_{1}$ is defined by

$$
C_{1}=\frac{i_{L 1} D}{\Delta V_{C 1} 2 f}
$$

The inductance $\mathrm{L}_{1}$ is calculated considering the cutoff frequency $f_{1}$. As a design parameter, it is adopted that $f_{1}$ must present a value 10 times lower than the current ripple frequency of dc bus, which shows twice the switch frequency $f$. Thus, the inductance $\mathrm{L}_{1}$ is defined by

$$
L_{1}=\frac{1}{\left(2 \pi f_{1}\right)^{2} C_{1}}
$$

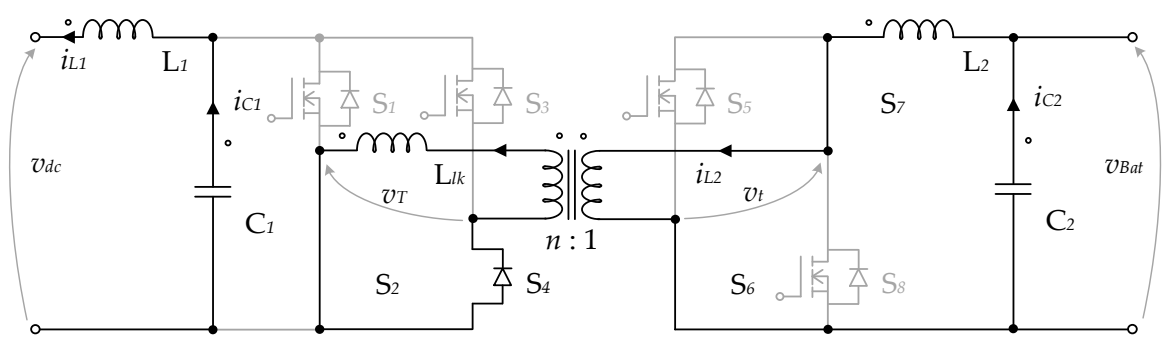

(a)

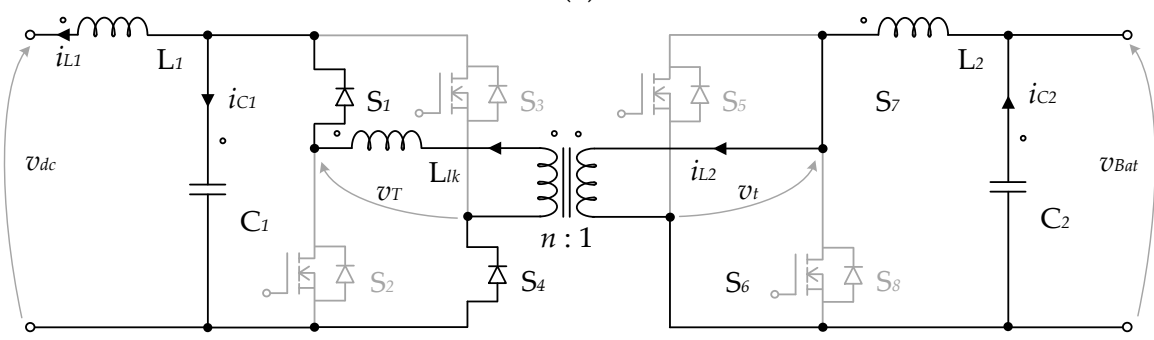

(b)

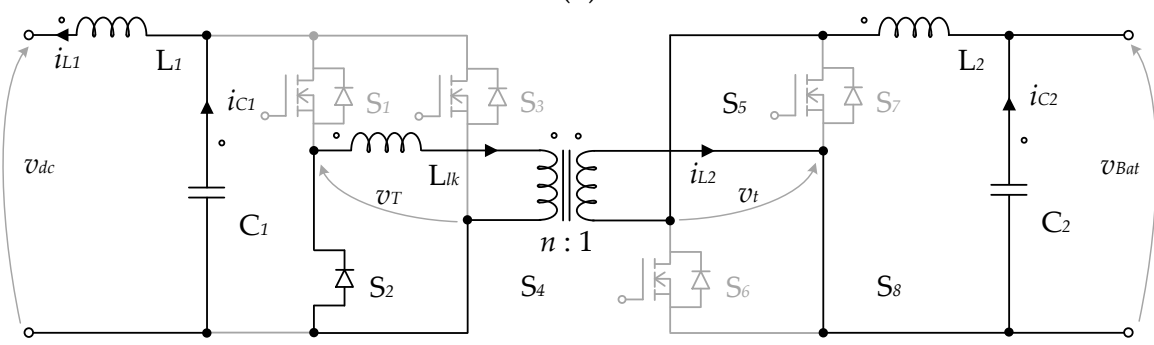

(c)

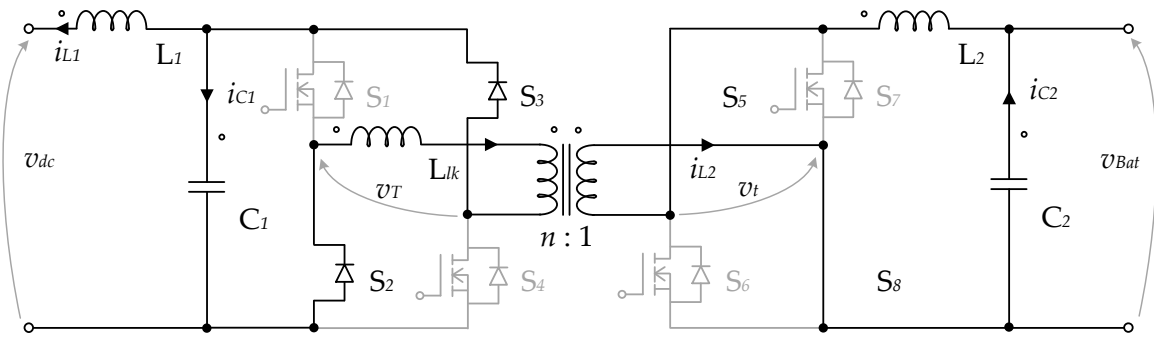

(d)

Figure 4. Equivalent circuits of the converter power stages operating in step-up mode, during battery discharging: (a) Stage 1, (b) Stage 2, (c) Stage 3, (d) Stage 4. 


\subsection{Theoretical Waveforms}

From the converter analysis, Figure 5 presents the theoretical waveforms of the converter operating in the step-down mode (Figure 5a) and step-up mode (Figure 5b). In both cases, the current and voltage filters $\left(C_{1}, L_{2}\right.$, and $\left.C_{2}\right)$ present ripple frequency with twice the switching frequency.

The voltages $v_{S 1}-v_{S 8}$ represent the blocking voltage under the semiconductors $\left(\mathrm{S}_{1}-\mathrm{S}_{8}\right)$ and can be used to verify the proposed modulations. Also shown in Figure 5 are the waveforms in the high-frequency filters and the current and voltage in the insulating transformer.

It is necessary to note that, to the converter invert, the current in the transformer, the leakage inductance must be firstly demagnetized. Then, it is magnetized with an opposite voltage. This results in two sub-stages between the intervals $T-t_{0}$ and $t_{2}-t_{3}$ in the step-up mode, when the diodes, $S_{1}$ or $\mathrm{S}_{3}$, start to conduct before the diodes, $\mathrm{S}_{2}$ or $\mathrm{S}_{4}$, shown in the Stages 2 and 4 , respectively. However, this does not affect the analysis of the converter because it represents a small time during the converter-switching period.

Due to this, the sub-stages related to the current inversion and semiconductors overlap/dead-band are not shown in this paper.

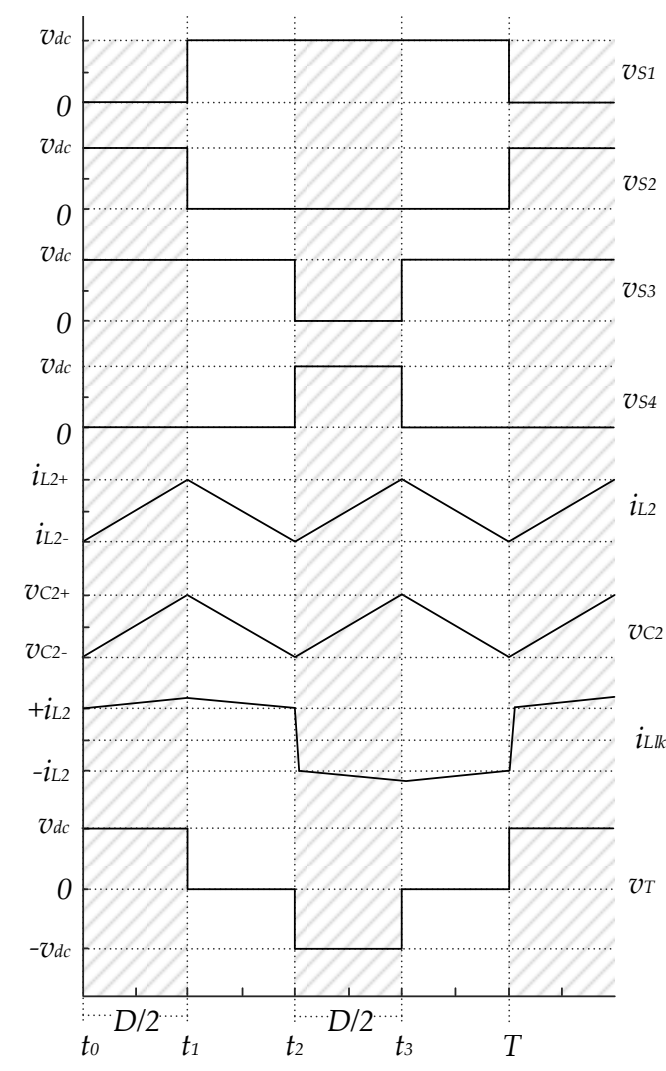

(a)

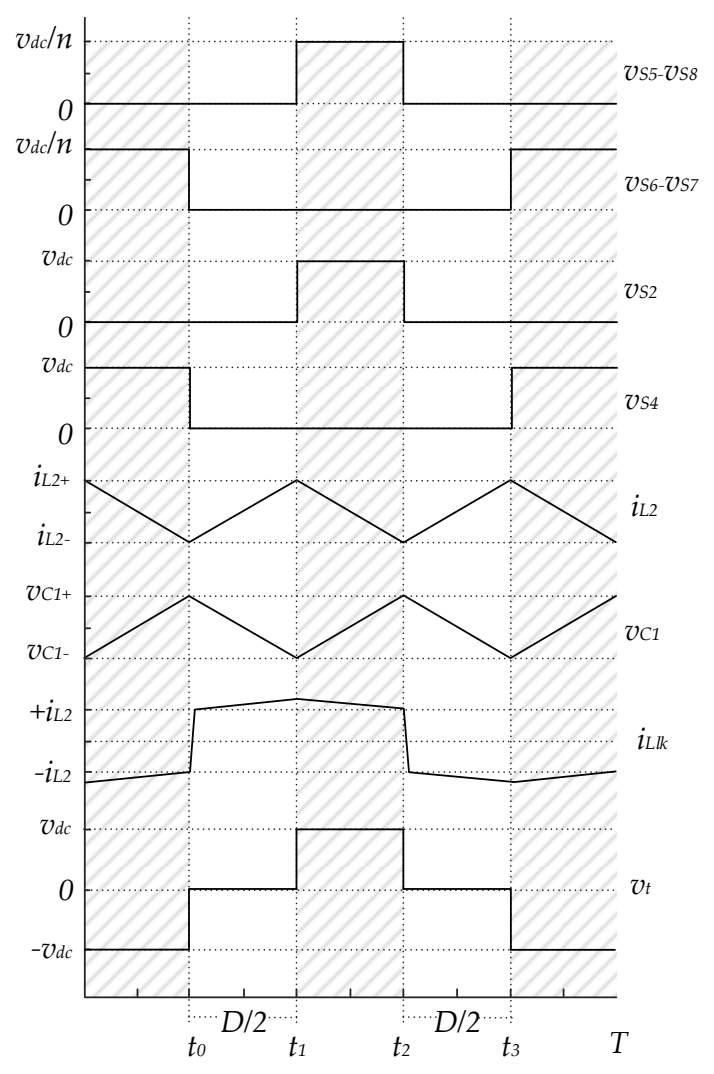

(b)

Figure 5. Theoretical waveforms of the converter operating in: (a) Step-down mode during the batteries' charge, (b) step-up mode during the batteries' discharge.

\subsection{Converter Design}

To define the transformer turns' ratio (n:1), the nominal voltage of dc bus $(230 \mathrm{~V})$ and battery bank $(60 \mathrm{~V})$ were initially defined. It was assumed, for the battery bank, values were in a range of 48-68.4 V, according to the battery state of charge (SoC).

Figure 6 exposes the relation of the duty-cycle $(D)$ with the transformer turns' ratio $(n: 1)$, and the 2:1 ratio was chosen for the transformer design. Therefore, it was possible to guarantee that, for the different modes and operating conditions, the converter operated at a duty-cycle between 0.4 and 
0.6. In this way, it was possible to avoid high modulation indexes-which increase the conduction losses - and to ensure a good excursion range for the control action.

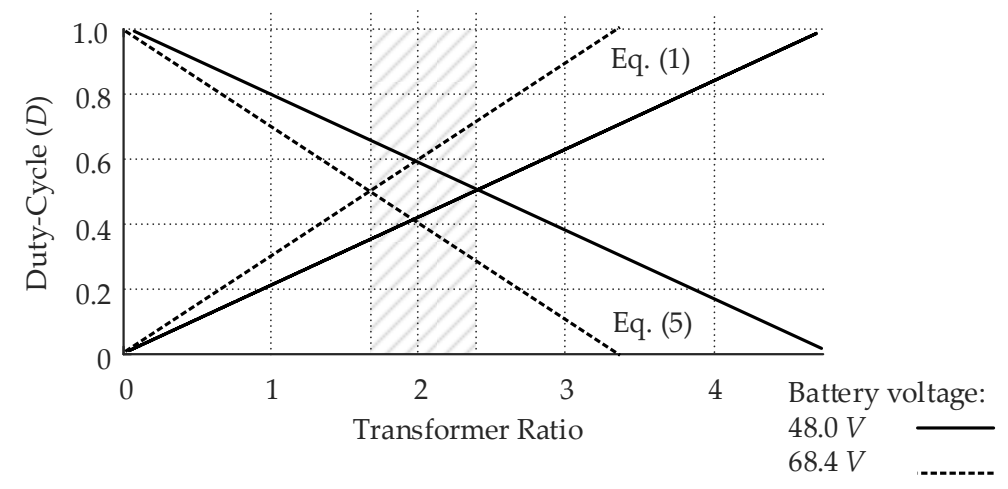

Figure 6. Duty-cycle variations for different values of $n$ and different battery voltage levels.

In Figure 7, it is presented the normalized curves relating the values of $C_{1}, C_{2}$, and $L_{2}$ with the variations of the $D$. In Table 1, the designed converter is presented, considering $50 \mathrm{kHz}$ as the switching frequency.
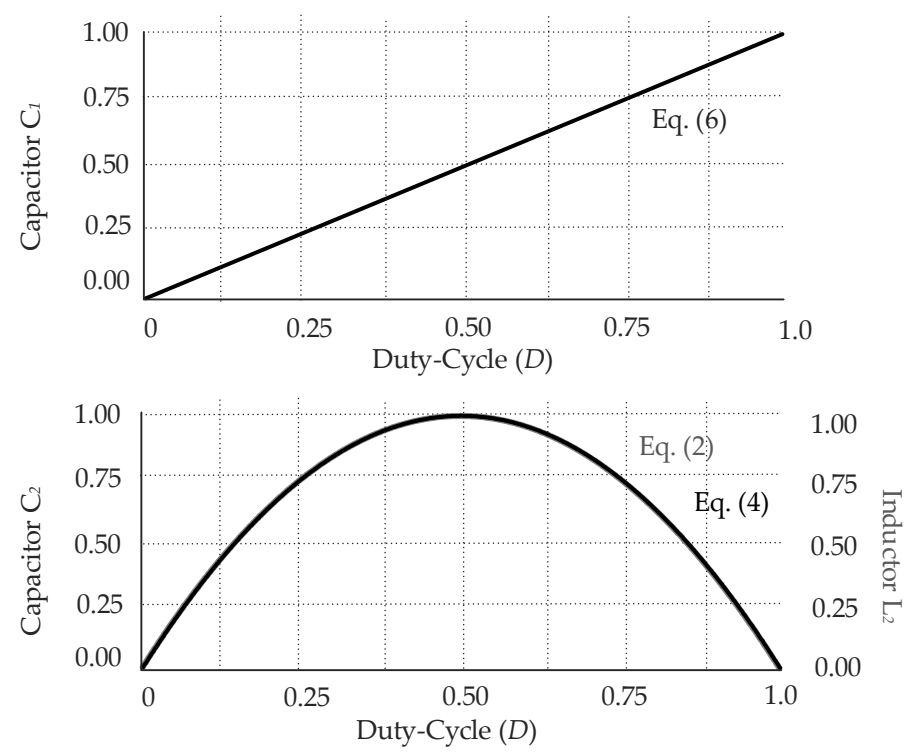

Figure 7. Filters' design for duty-cycle converter variations.

Table 1. Details of designed converter.

\begin{tabular}{cc}
\hline Parameters & Specifications \\
\hline dc bus & Nominal voltage: $230 \mathrm{~V}\left(\mathrm{C}_{\mathrm{B}}=22 \mu \mathrm{F}\right)$ \\
& Nominal power: $200 \mathrm{~W}$ \\
& Maximum voltage ripple: $11.5 \mathrm{~V}$ \\
\hline & Nominal voltage: $60 \mathrm{~V}(5 \times 12 \mathrm{~V})$ \\
Battery bank & Capacity: $17 \mathrm{Ah}$ \\
(CBS P12170) & Internal Resistance: $0.108 \Omega$ \\
& Charge current: $0.87 \mathrm{~A}-1.70 \mathrm{~A}$ \\
& Maximum current ripple: $0.2 \mathrm{~A}$ \\
& Maximum voltage ripple: $6 \mathrm{~V}$ \\
\hline
\end{tabular}


Table 1. Cont.

\begin{tabular}{|c|c|c|}
\hline Parameters & \multicolumn{2}{|c|}{ Specifications } \\
\hline Transformer & $\begin{array}{r}\text { Pri: } 18 \\
\text { Sec: } 9 \\
\text { Core: } 1 \\
\text { Total leakag }\end{array}$ & $\begin{array}{l}\text { X\#24 AWG } \\
\text { x\#24 AWG } \\
\text { tT40.31.10B } \\
\text { tance: } 0.538 \mu \mathrm{H}\end{array}$ \\
\hline Inductor $\mathrm{L}_{1}$ & $0.54 m \mathrm{H}$ & $\begin{array}{c}16 \text { turns } 4 x \# 26 \text { AWG } \\
\text { Core: EE 30/14/07 }\end{array}$ \\
\hline Capacitor $C_{1}$ & $470 n \mathrm{~F} \times 250 \mathrm{~V}$ & \\
\hline Indutor $\mathrm{L}_{2}$ & $1.44 m \mathrm{H}$ & $\begin{array}{c}80 \text { tuns } 7 x \# 26 \text { AWG } \\
\text { Core: } \mathrm{EE} 42 / 21 / 15\end{array}$ \\
\hline Capacitor $C_{2}$ & $47 n \mathrm{~F} \times 150 \mathrm{~V}$ & \\
\hline
\end{tabular}

\section{Modeling and Transient Analysis}

For the system representation, which involves the converter and the battery, the average model on state-space analysis was adopted. To obtain the mathematical models, the transformer leakage inductance was disregarded. This was possible because, in this proposal, the leakage inductance was made as small as possible due to the converter operation not depending on the transformer inductance. The leakage inductance was not responsible to store energy. The inductor $\mathrm{L}_{2}$ had this responsibility, as presented in Section 2. This allowed the converter to be analyzed through an average model, which is a simple and well-known approach $[23,24]$. This is an advantage of this proposal.

The approaches for modeling presented in previous literature considered the transformer because it was also used to store energy and, consequently, the leakage inductance was considerable [11,14]. In these cases, the leakage inductance had a significant value and it impacted the converter operation. In addition, since the transformer current showed a large alternated component, the average model could not represent the converter operation due to the zero-mean characteristic of the transformer current. Therefore, other laborious modeling techniques were needed $[18,19]$.

\subsection{Modeling of the Converter on the Step-Down Mode}

In this operation mode, it was necessary to regulate either the charging current or the batteries' voltage, according to their SoC.

For the representation of the battery bank, the equivalent Thevenin circuit was considered. This circuit does not consider SoC variations. However, it was previously known that the dynamic related to the batteries' charge is a slow process, which does not represent a great impact on the transient response of the converter operating at high frequencies.

To simplify the transient analysis, the modeling was performed considering that: (1) The transformer was ideal; (2) the capacitor $C_{1}$ was large enough so that $v_{C 1}=v_{d c}$; therefore, the system could be simplified by a second-order model; and (3) as state variables, $X_{1}=i_{L 2}$ and $X_{2}=v_{C 2}$ were adopted.

According to the analysis of the power stages, the state-space matrices are:

$$
\left\{\begin{array}{c}
A_{13}=\left[\begin{array}{cc}
0 & -\frac{1}{L_{2}} \\
\frac{1}{C_{2}} & -\frac{1}{C_{2} R_{\text {Bat }}}
\end{array}\right], B_{13}=\left[\begin{array}{c}
\frac{v_{d c}}{n L_{2}} \\
0
\end{array}\right] \\
A_{24}=\left[\begin{array}{cc}
0 & -\frac{1}{L_{2}} \\
\frac{1}{C_{2}} & -\frac{1}{C_{2} R_{\text {Bat }}}
\end{array}\right], B_{24}=\left[\begin{array}{l}
0 \\
0
\end{array}\right]
\end{array}\right.
$$


in which, the power Stages 1 and 3 are represented by the matrices $A_{13}$ and $\boldsymbol{B}_{13}$ and the power Stages 2 and 4 are given by $\boldsymbol{A}_{24}$ and $\boldsymbol{B}_{24}$. The system is represented using the weighted average,

$$
\left\{\begin{array}{l}
\boldsymbol{A}=\boldsymbol{A}_{13} D+A_{24}(1-D)=A_{13}=A_{24} \\
\boldsymbol{B}=\boldsymbol{B}_{13} D+\boldsymbol{B}_{24}(1-D)=\boldsymbol{B}_{13} D
\end{array}\right.
$$

Therefore, the average model in state-space is given by:

$$
\left\{\begin{array}{c}
\dot{X}=A X+B D(t) \\
Y=C X
\end{array}\right.
$$

where $D(t)$ represents the converter duty-cycle and the matrix $\mathbf{C}=\left[\begin{array}{ll}10 & 0\end{array}\right]$ considers the current $i_{L 2}$ as the output variable.

From the analysis of Equations (8) and (9) it is possible to verify that the eigenvalues of the system are independent of the duty-cycle $D(t)$. Therefore, Equation (10) is valid for a wide range of converter operations. Thus, the obtained model represents a clear advantage due to the proposed modulation strategy, when compared to linearized and small-signals' models that arise in DAB converters with PS or frequency modulations $[17,18]$. Even being an average model, Equation (10) is directly dependent on the control variable $D(t)$, resulting in a large-signals' model. This feature allows representing the system with a simplified and generalized model that is valid over all the operational range of the converter.

Considering the parameters described in Table 1, the Equation (10) results in the following transfer function:

$$
G_{A}(s)=\frac{i_{L 2}(s)}{D(s)}=\frac{4.792 \times 10^{4} s+9.427 \times 10^{11}}{s^{2}+1.967 \times 10^{7} s+1.478 \times 10^{9}}
$$

It was possible to observe that the converter model was directly dependent on duty cycle $(D)$ and, therefore, the control could be performed directly through a PWM strategy. Reference $[17,19]$, due to the PS and frequency modulation, the large-signal model was not sufficient to model the plant. Therefore, for these cases, it was necessary to develop a linearized and small-signal model, which is more complex and also impacts the design and relative stability of the control system.

To validate the model, the transfer function of Equation (11) was simulated in Matlab. Considering that the battery voltage was initially $55.20 \mathrm{~V}$, a duty cycle equal to 0.48 was applied to the system. This value resulted in the nominal charging current $(1.7 \mathrm{~A})$. The same test was realized in the experimental setup to compare the open-loop theoretical response with the experimental result of the prototype. The comparison between the model simulation and the experimental result is shown in Figure 8, which validates the obtained average model.

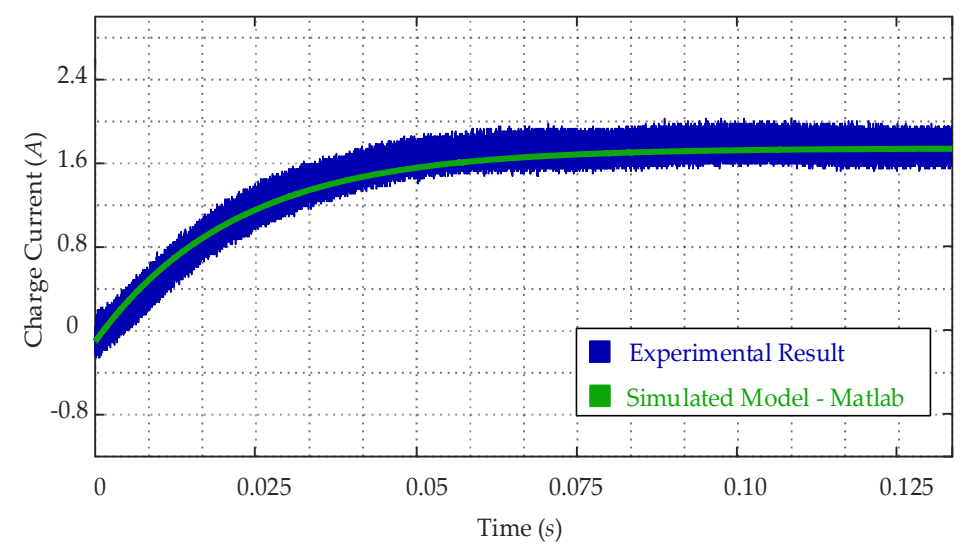

Figure 8. Validation of the converter model on the charging mode (step-down mode). 
When the battery reaches a predefined voltage level indicating that the charging process is almost completed the constant current charge mode is switched to a constant voltage charge mode. Hence, to design the controller, an appropriate transfer function describing the plant must be obtained. The transfer function that relates the battery voltage $v_{\mathrm{C} 2}$ with $D(s)$ is given by Equation (12). It was obtained from Equation (8), considering $v_{\mathrm{C} 2}$ as the output variable. In this charging mode, the control design objective is to keep the battery voltage constant. Therefore, the steady-state error is important in this analysis. Considering that the eigenvalues of Equation (8) do not vary due to the output matrix C, for simplification of design, the same controller used for the current loop can be used for the voltage control loop.

$$
G_{A}^{\prime}(s)=\frac{v_{C 2}(s)}{D(s)}=\frac{5.176 \times 10^{4} s+1.019 \times 10^{11}}{s^{2}+1.967 \times 10^{7} s+1.478 \times 10^{9}}
$$

\subsection{Modeling of the Converter on the Step-Up Mode}

To obtain the converter model for the battery discharging mode, each step of operation must be individually analyzed again, considering the previously presented equivalent circuits in Figure 4.

For modeling purposes, considering a possible power supply failure, the dc bus is represented by $\mathrm{R}_{O}$, proportional to the nominal power of the converter connected to the dc bus. In this way, $X_{1}=i_{L 1}$, $X_{2}=v_{C 1}$, and $X_{3}=i_{L 2}$ are taken as the state variables. According to the analysis of the power stages, the state-space matrices are given by

$$
\left\{\begin{array}{c}
A_{13}=\left[\begin{array}{ccc}
-\frac{R_{O}}{L_{1}} & \frac{1}{L_{1}} & 0 \\
-\frac{1}{C_{1}} & 0 & 0 \\
0 & 0 & 0
\end{array}\right], B_{13}=\left[\begin{array}{c}
0 \\
0 \\
\frac{v_{\text {Bat }}}{L_{2}}
\end{array}\right] \\
A_{24}=\left[\begin{array}{ccc}
-\frac{R_{O}}{L_{1}} & \frac{1}{L_{1}} & 0 \\
-\frac{1}{C_{1}} & 0 & \frac{1}{n C_{1}} \\
0 & -\frac{1}{n L_{2}} & 0
\end{array}\right], B_{24}=\left[\begin{array}{c}
0 \\
0 \\
\frac{v_{\text {Bat }}}{L_{2}}
\end{array}\right]
\end{array}\right.
$$

where the power Stages 1 and 3 are represented by matrices $A_{13}$ and $B_{13}$ and the power Stages 2 and 4 are given by $\boldsymbol{A}_{24}$ and $\boldsymbol{B}_{24}$.

Due to the non-linearity of the converter static-gain defined by Equation (5) in the step-up mode, for control purposes, a small-signal approach is required to allow the use of a PWM modulation. This is a characteristic of current-fed configurations [7]. However, this issue is not critical, since the dc bus operates on a fixed-voltage level and, consequently, with a well-defined operation point. This is an advantage of the proposed approach for the bidirectional converter.

The small-signal average model of any converter is defined through the analysis of deviations around the operation point of the system. From this principle, the analysis presented by [23] results in the model given by:

$$
\begin{gathered}
\dot{\hat{x}}=A \hat{x}+B_{S} d \\
y=C \hat{x}
\end{gathered}
$$

where $\boldsymbol{B}_{s}=\left(\boldsymbol{A}_{1}-\boldsymbol{A}_{2}\right) \cdot\left(-\boldsymbol{A}^{-1} \boldsymbol{B}\right)+\left(\boldsymbol{B}_{1}-\boldsymbol{B}_{2}\right)$ and $d$ represents deviations of the converter duty-cycle around its operation point.

Considering the parameters presented in Table 1, from (14), the transfer function that represents the small-signals' model is defined by Equation (15), which relates the $v_{d c}$ with the duty-cycle variations, around the operation point $D=0.48$ and $v_{d c}=230 \mathrm{~V}$.

$$
G_{B}(s)=\frac{v_{d c}(s)}{d(s)}=\frac{-2.29 \times 10^{6} s^{2}-1.05 \times 10^{12} s+2.18 \times 10^{16}}{s^{3}+4.802 \times 10^{5} s^{2}+4.08 \times 10^{9} s+7.86 \times 10^{13}}
$$

To validate the model obtained, experimental and simulation results were used. Initially, the converter was simulated with a duty-cycle equal to 0.40 . For this operation point, the dc bus voltage 
is equal to $200 \mathrm{~V}$. After a period of $1.50 \mathrm{~ms}$, a 0.08 disturbance $(d)$ was applied on the duty-cycle, resulting in a voltage of $230 \mathrm{~V}$. The converter was tested in the laboratory with the same operation points. Both responses are compared in Figure 9, where their similarity is observed.

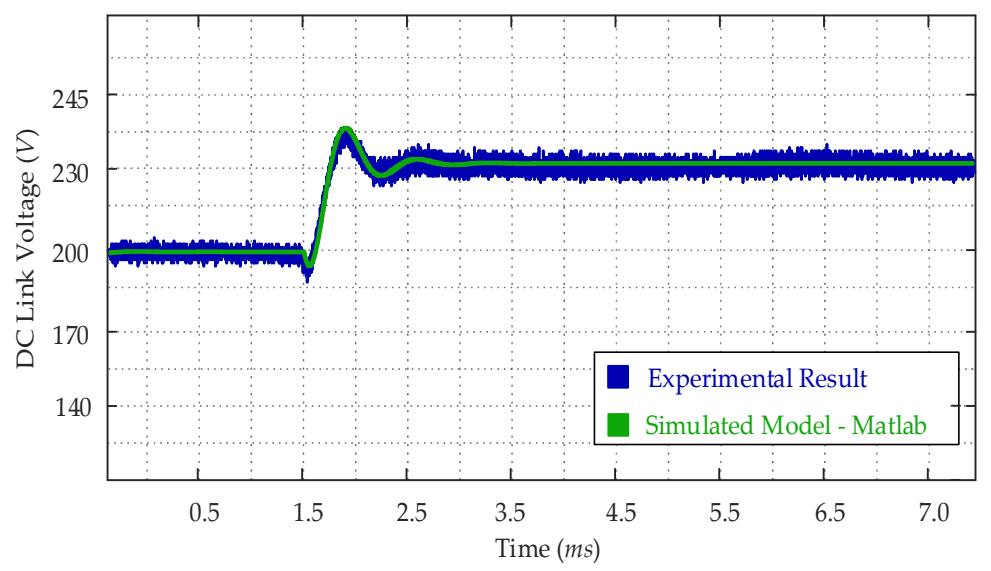

Figure 9. Validation of the converter model on the discharging mode (step-up mode).

Based on the transfer functions described by Equations (11) and (15), the design of the control system is described in the next section.

\subsection{Control System Design}

To charge the battery bank, the transfer function given by Equation (11) was considered to design the controller. The controller must follow a constant current reference with a null error in steady-state. As a design parameter, a cutoff frequency of $50 \mathrm{~Hz}$ was chosen for the compensated system. As control strategy, a proportional-integral (PI) controller with fixed gains was chosen. The controller zero was used to compensate the dominant pole of the transfer function of Equation (11), which was at -75.14 . Regarding the proportional gain, 0.0058 was evaluated to meet the cutoff frequency. The result is shown in the frequency responses of Figure 10a, which compares the open-loop system with the compensated plant. In Figure 10b, the closed-loop step response is shown, which presents a settling time of $20 \mathrm{ms,}$ without overshoot.

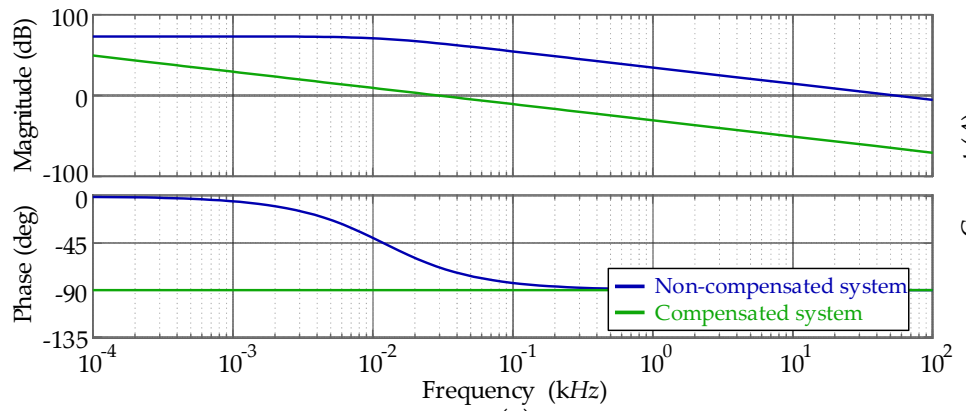

(a)

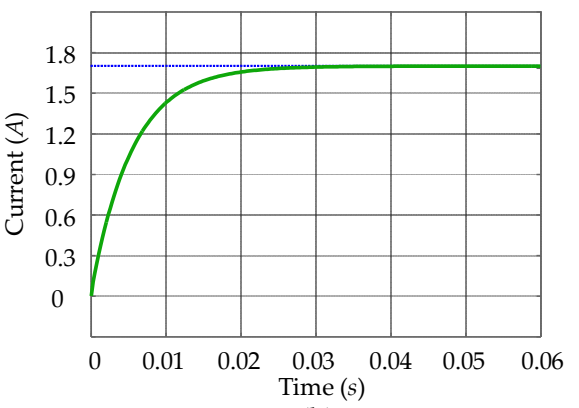

(b)

Figure 10. Simulation results: (a) Open-loop frequency response of the converter without compensator and with the compensator for the battery charging mode, (b) closed-loop step response.

Both systems, with and without the compensator, shown an infinite gain margin and $90^{\circ}$ phase margin. The designed controller is given by

$$
C_{i L 2}(s)=\frac{0.0058 s+0.4346}{s}
$$


The internal resistance $\left(\mathrm{R}_{B a t}\right)$ of the lead-acid batteries increases during the discharge. The variation of the internal resistance comparing a fully charged and a depleted battery was about $40 \%$, according to the $[25,26]$. To investigate the effects of the parametric variation related to $R_{b a t}$, Figure 11 shows the dominant closed-loop poles and zero for different parameters.

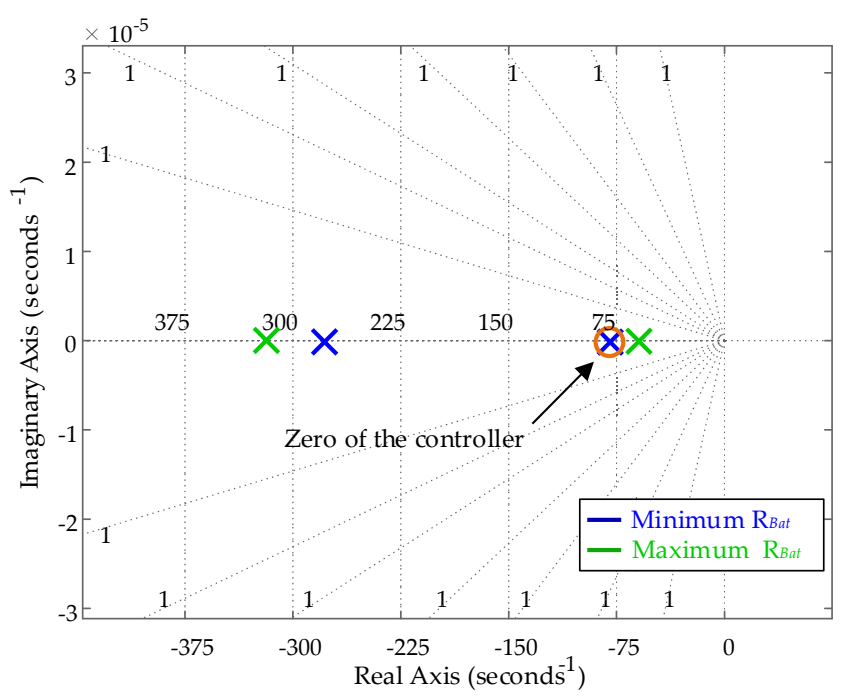

Figure 11. Closed-loop pole, zero for different values of the battery internal resistance $\mathrm{R}_{b a t}$.

When $\mathrm{R}_{b a t}$ was minimum, the zero of the controller canceled one pole of the plant. The dominant closed-loop pole is represented in blue in the figure. Another pole, not shown in the figure, appeared at $-1.970 \times 10^{7}$, near the other zero at $-1.970 \times 10^{7}$.

When $\mathrm{R}_{b a t}$ was maximum, the zero of the controller did not cancel any one pole of the plant. Therefore, this pole appeared slightly at the right of the zero of the controller. The second closed-loop pole (in green) was displaced to the left of the pole of the previous case. Finally, a third pole, not shown in the figure, appeared at $-1.407 \times 10^{7}$, near the other zero at $-1.407 \times 10^{7}$.

It is possible to note that the system was stable for different values of $R_{B a t}$. When $R_{b a t}$ decreased (battery charging), the dominating closed-loop poles moved towards each other on the map. Therefore, system stability margins were increased. The high-frequency poles had little effect on the dynamic behavior of the system.

For the battery discharging mode, the Equation (14) was considered to design the controller. The controller must regulate the dc bus voltage in a reference of $230 \mathrm{~V}$. As a design parameter, a $50 \mathrm{~Hz}$ cutoff frequency was chosen for the compensated system.

By the analysis of Equation (14), it was verified that the non-compensated system had two dominant poles on $-4145 \pm j 12221$. As a control strategy, a proportional-integral-derivative (PID) controller was chosen, with zeros in $-4145 \pm j 12221$. The proportional gain was $4.14 \times 10^{-9}$, resulting in the controller given by

$$
C_{v d c}(s)=\frac{4.114 \times 10^{-9} s^{2}+3.406 \times 10^{-5} s+0.6848}{s}
$$

The result is shown in the frequency responses of Figure 12a, which compares the open-loop system with the compensated plant. The non-compensated system had a $-49 \mathrm{~dB}$ of gain margin and $-89.5^{\circ}$ of phase margin. The compensated system had infinite gain margin and $90^{\circ}$ phase margin. Again, in Figure 12b, the closed-loop step response is shown, which presents a settling time of $20 \mathrm{ms,}$ without overshoot. 


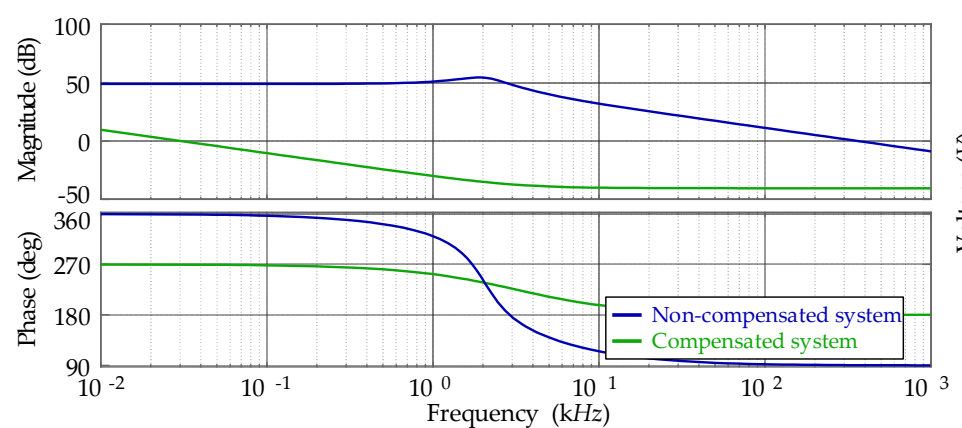

(a)

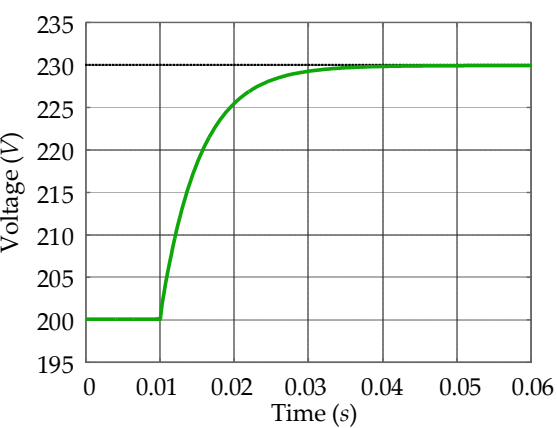

(b)

Figure 12. Simulation results: (a) Open-loop frequency response of the converter without compensator and with compensator for the battery discharging mode, (b) closed-loop step response.

\section{Experimental Results}

The general structure of the control system is shown in Figure 2 and the main elements of the system are described in Table 1. The current measurements were provided by hall-effect sensors model ACS712 from Allegro MicroSystems, while the voltages were also measured by hall-effect sensors model LV-25P from LEM. The controllers of the Equations (15) and (16) were discretized using the Tustin method. The sampling frequency was $50 \mathrm{kHz}$. The PWM frequency was $50 \mathrm{kHz}$. The digital processor used was the DSP Delfino F28337S, where the modulation strategy and control loops were implemented. The main results were acquired using a Tektronix DP04034 oscilloscope.

For the battery charge test, different reference values were adopted to verify the converter transient response. The values were chosen according to the battery manufacturer's instructions, resulting in $0.20 \mathrm{~A}$ and $1.70 \mathrm{~A}$. According to the results shown in Figure 13, the current $i_{L 2}$ followed the reference value, without steady-state error or overshoot. The battery and transformer voltage were also shown to verify the converter operation. Related to the transient response, it was verified a settling time approximately $20 \mathrm{~ms}$. This result was according to the control design and the simulations results presented in Figure 10.

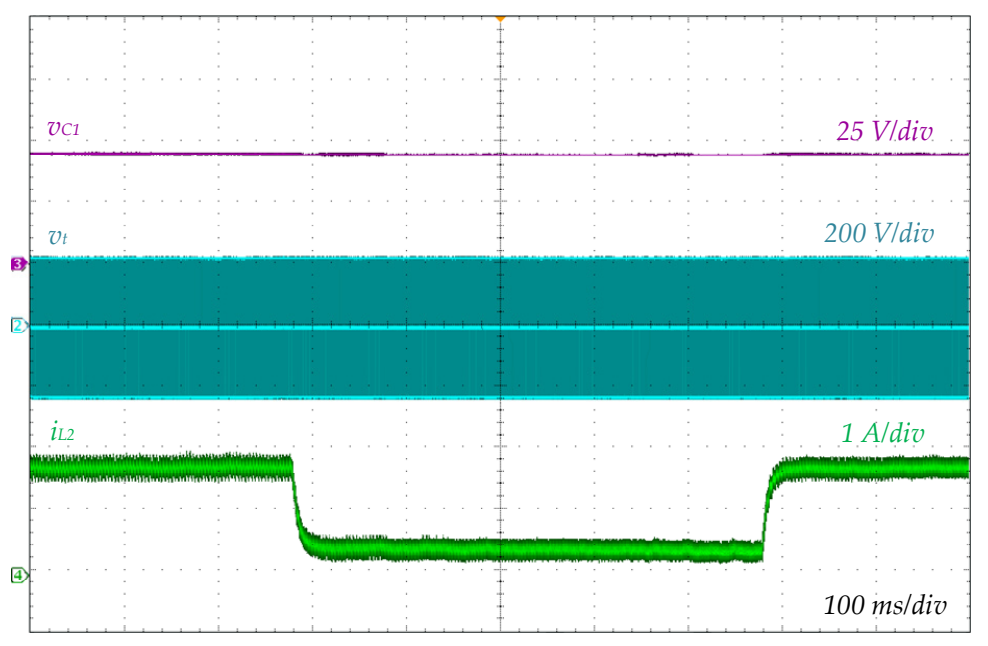

Figure 13. Closed-loop response of converter CFDAB controlling the battery charge current.

A second test was performed to evaluate the robustness of the control design. Due to the long time charging, different results were obtained during the evolution of the batteries' state of charge. Initially, the battery bank was charged with a constant current, equal to $1.7 \mathrm{~A}$, starting from the initial condition of $48 \mathrm{~V}$. The result is illustrated in Figure 14a. After some time of charging, the battery voltage was approximately $68 \mathrm{~V}$ and the charging current remained at $1.7 \mathrm{~A}$, as presented in Figure 14b. These results proved that the controller operated adequately in a wide range of the converter operation. 


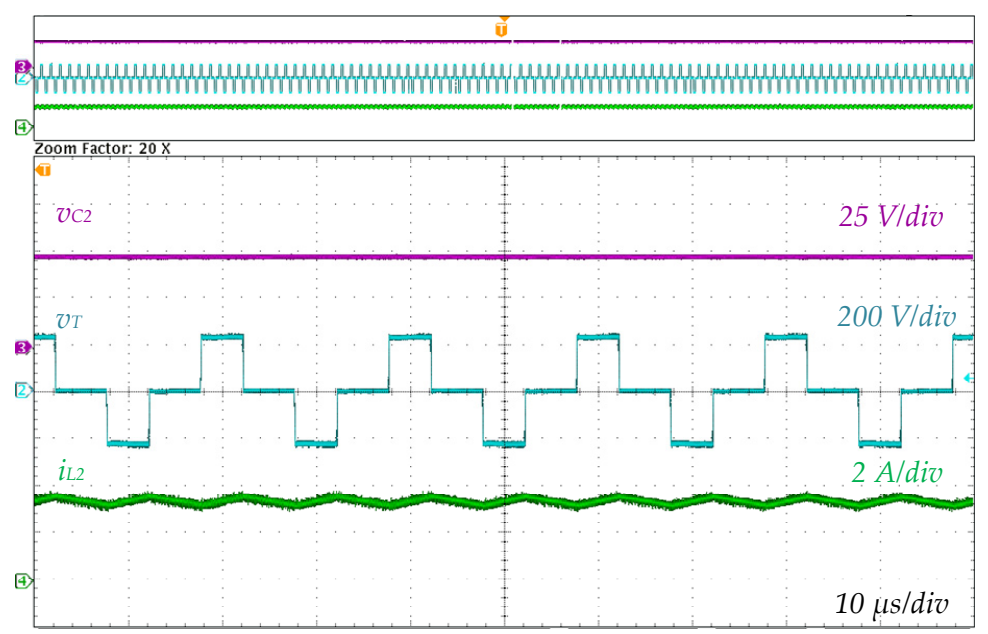

(a)

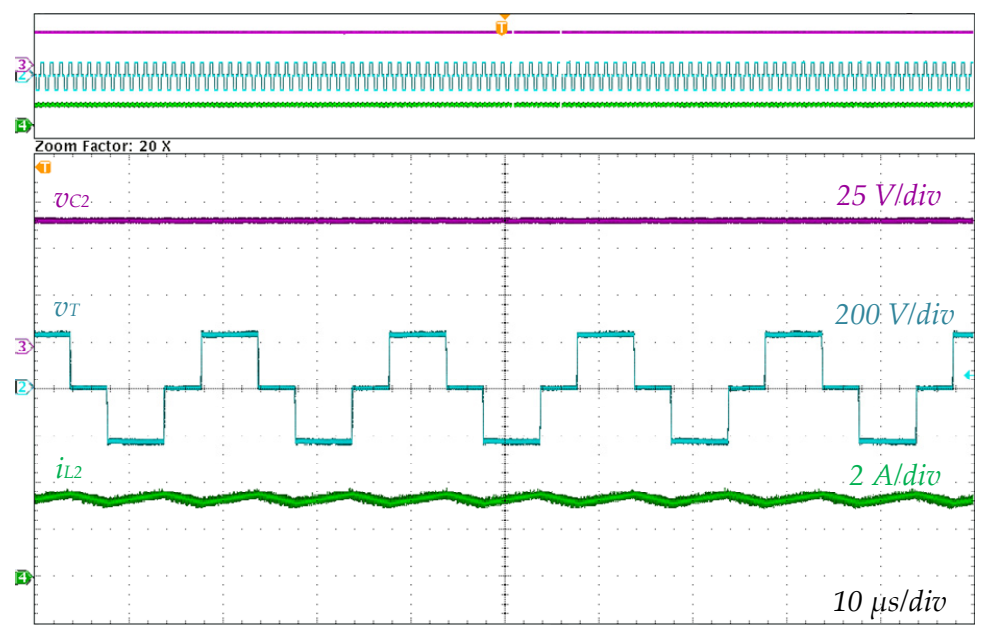

(b)

Figure 14. Charge current control during the batteries charge process: (a) Low state of charge and regulation of the charge current, $(\mathbf{b})$ high state of charge and regulation of the charge current.

To analyze the converter closed-loop response during the full charge process, a long-term test was carried out. The data were collected through a National Instruments data acquisition interface model NI USB-6269 with the aid of LabVIEW. The result is illustrated in Figure 15. Initially, the battery was charged with constant current equal to $1.70 \mathrm{~A}$. During this time period, the battery voltage gradually rose to the maximum value indicated by the manufacturer $(68.4 \mathrm{~V})$. From this point, the control must operate at constant voltage mode until the batteries were fully charged. This result evidenced the correct operation of the control system for a wide range of battery SoC, consistent with the previous results, shown in Figure 14.

For the batteries' discharge, or step-up mode, initially, the transient response of the closed-loop converter was verified, considering $200 \mathrm{~V}$ and $230 \mathrm{~V}$ as the dc bus voltage reference. The results are shown in Figure 16.

Concerning the steady-state operation, the main waveforms are shown in Figures 17 and 18, where are present the voltage waveforms of semiconductors, transformer current, voltage, and ripple in the high-frequency filters $\left(\mathrm{C}_{1}-\mathrm{L}_{2}-\mathrm{C}_{2}\right)$.

In Figure $17 \mathrm{~b}$ distortions in the voltage waveform in the secondary of the transformer are still verified. However, these were related to the quality of the semiconductors and not to the modulation. This problem was reported in [23] and it is due to the hard switching operation of the MOSFETs when substantial inductance $\left(\mathrm{L}_{2}\right)$ is present in series with the semiconductors. 
This is an intrinsic characteristic of CFDAB converter, and also occurred in other works, such as [11]. In such a scenario, a resonant circuit, composed by the MOSFET output capacitance and the series inductance, is excited when the MOSFET turns off, leading to some overshoot. However, according to the experimental results, this characteristic was not relevant to the converter operation as the voltages were within a safe zone of operation of the semiconductor.

On the high-voltage side, the MOSFETs operated in zero-voltage switching, and due to the soft switching, no overvoltage was verified. Details of the soft switching are not shown in this paper because this is a natural characteristic in PWM modulation, as shown in [24].

For the discharge mode, Figure 18a shows the semiconductors' voltages. Figure 18b,c depicts the transformer and dc bus voltage waveforms. Again, low voltage and current ripples were observed in the filters $\left(i_{L 2}\right.$ and $\left.v_{C 1}\right)$, with the converter being tested for different power levels, according to the load variations connected to the dc bus.

In Figure 18a, it is possible to note a small delay between the voltage waveforms of semiconductors $S_{5}$ and $S_{2}$, and $S_{7}$ and $S_{4}$. This represents the sub-intervals related to the conduction of the diode of the high-voltage side.
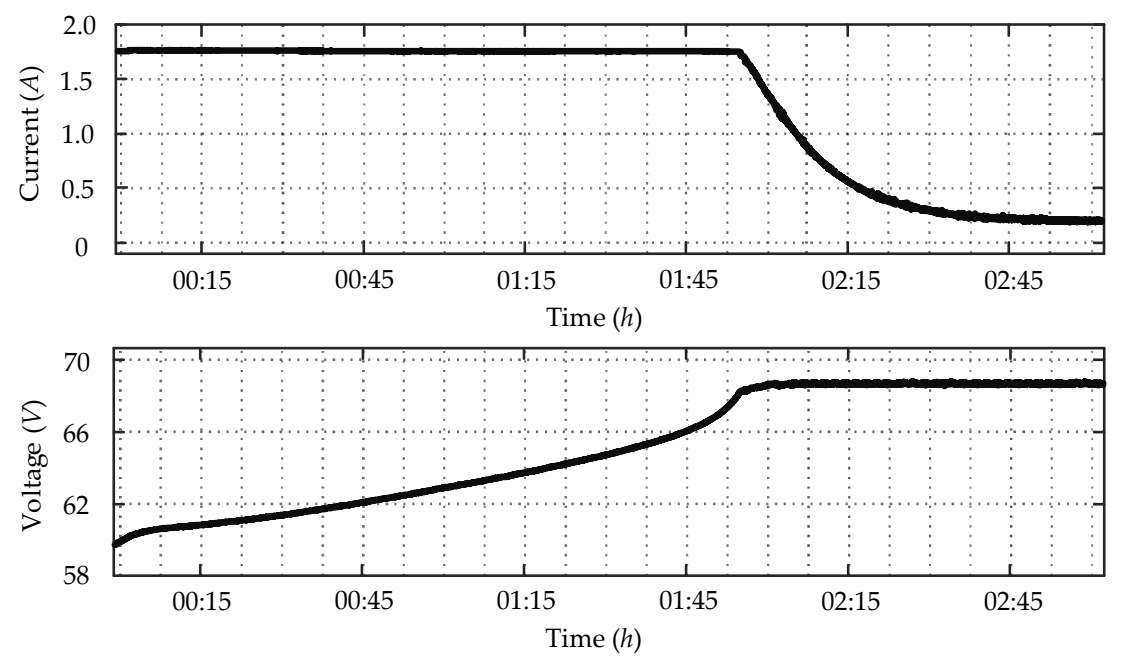

Figure 15. Experimental results for the batteries' charge process, including constant current charge mode and constant voltage charge mode.

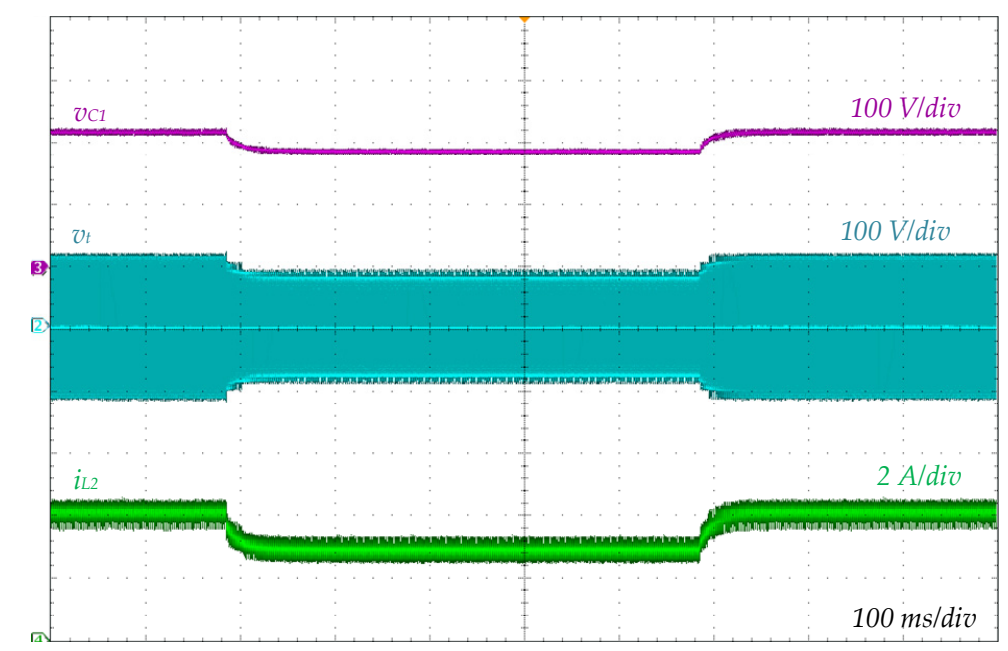

Figure 16. Closed-loop response of converter CFDAB controlling the dc bus voltage. 


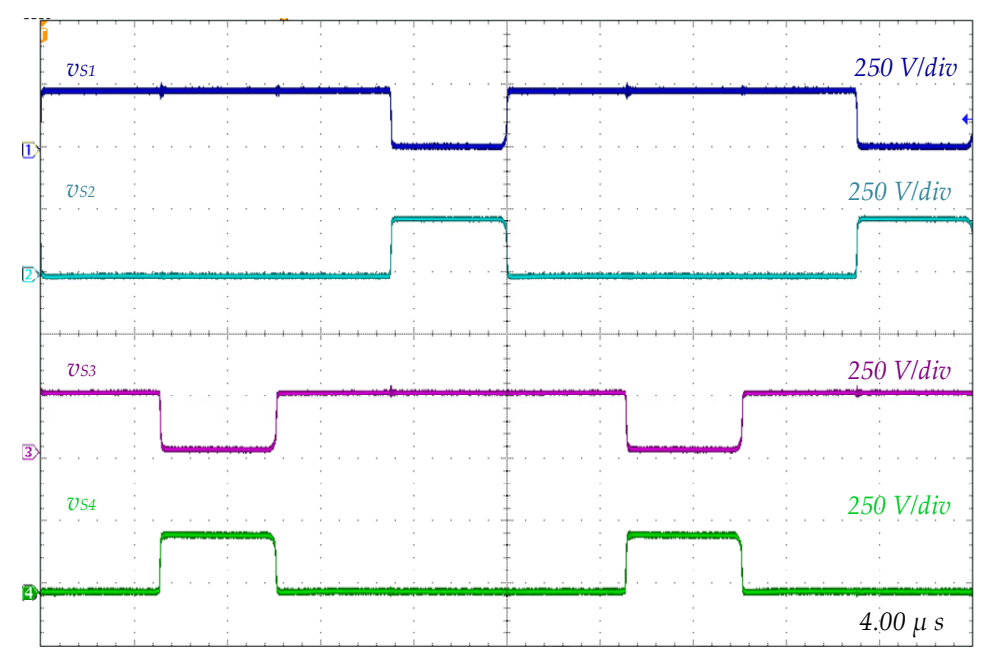

(a)

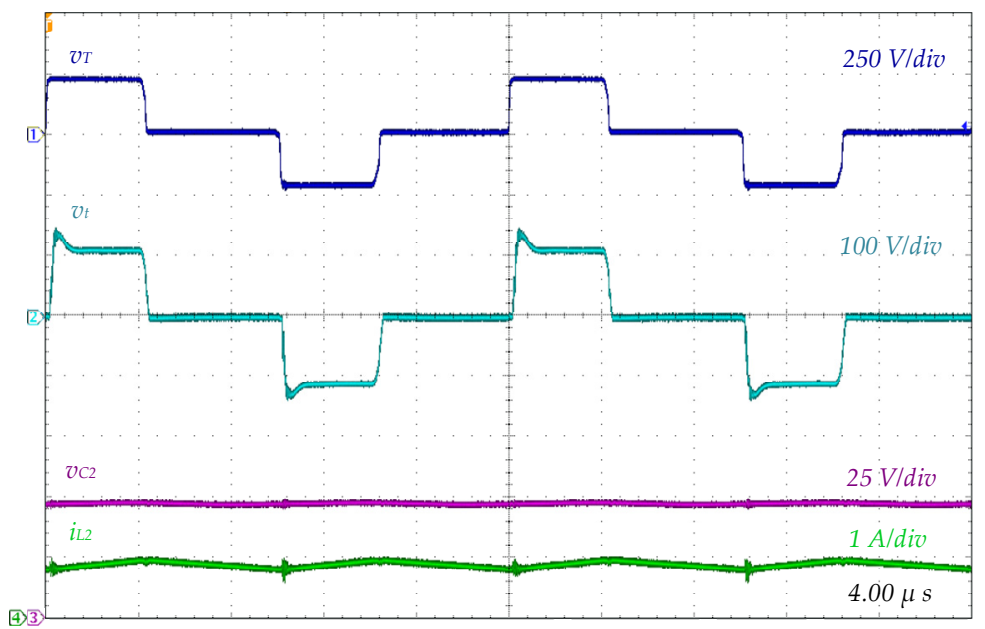

(b)

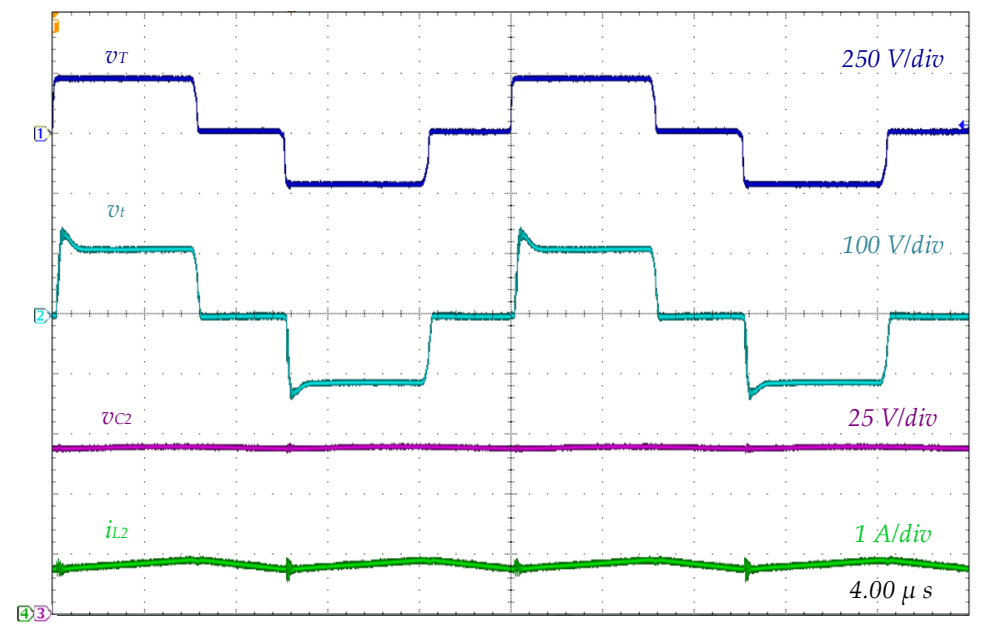

(c)

Figure 17. Steady-state operation of the converter operating in step-down mode: (a) Semiconductors' voltage, transformer voltages $\left(v_{T}, v_{t}\right)$, voltage $\left(v_{C 2}\right)$, and current ripple in the filters $\left(i_{L 2}\right)(\mathbf{b})$ for a duty-cycle equal to 0.48 , (c) for a duty-cycle equal to 0.69 . 


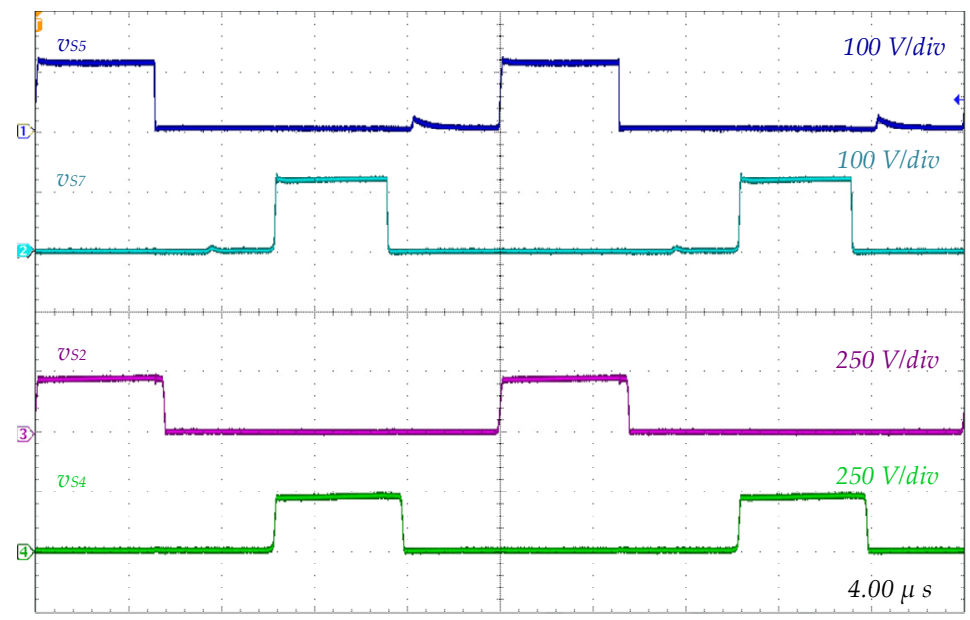

(a)

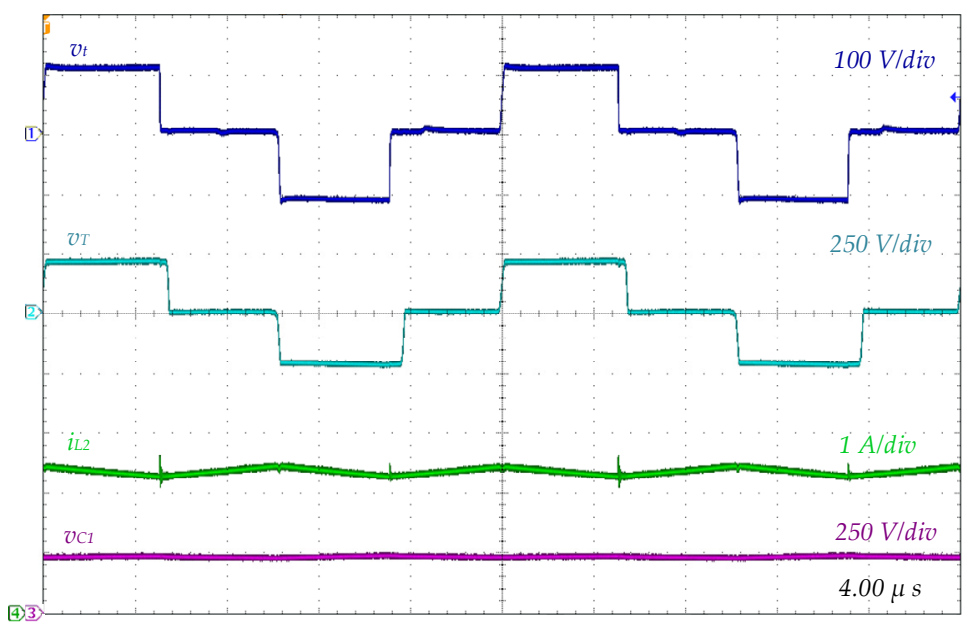

(b)

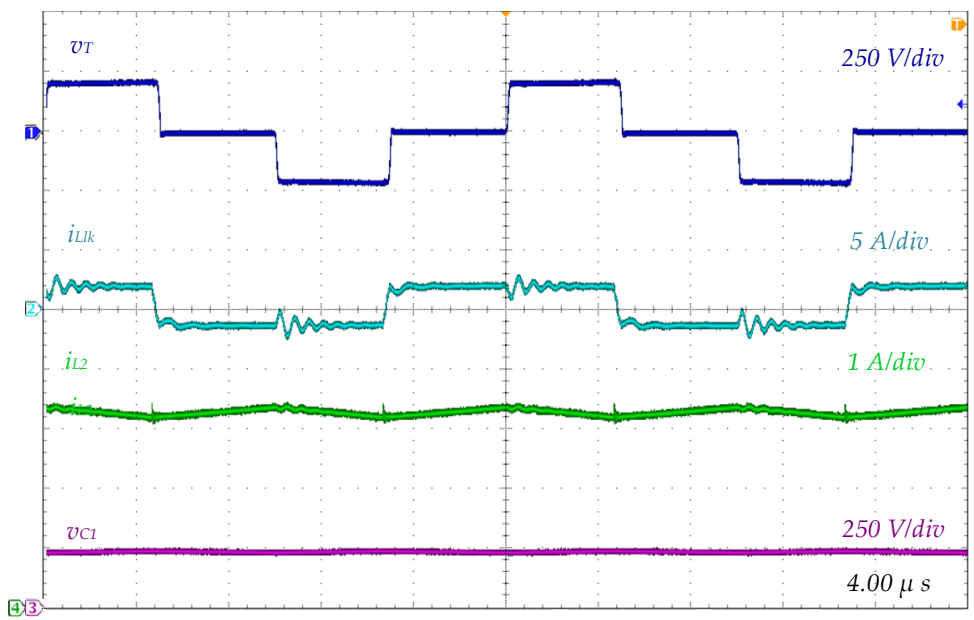

(c)

Figure 18. Steady-state operation of the converter operating in step-up mode: (a) Semiconductors' voltages, transformer voltages $\left(v_{T}, v_{t}\right)$, current $\left(i_{L l k}\right)$, voltage $\left(v_{C 1}\right)$, and current ripple in the filters $\left(i_{L 2}\right)$ (b) for a power equal to $100 \mathrm{~W}$, (c) for a power equal to $200 \mathrm{~W}$. 
Also, in Figure 18b, the transformer's current waveform is shown. This result was similar to the theoretical waveforms, shown in the analysis of Section 2. However, in the experimental results, it is possible to note small resonance in the transformer current waveform when compared to the theoretical waveforms. The resonance in the transformer current occurred when the diodes got into conduction and it as the interaction between the leakage inductance and the output capacitances of the semiconductors. However, the actual result did not significantly affect the converter operation.

\section{Discussion}

The conventional DAB converter was proposed, using the insulation transformer as an energy storage element. As a consequence, some hardware disadvantage was observed in this configuration due to the high current ripple in its transformer. The result was that the voltage filters were commonly implemented with electrolytic capacitors, which have greater problems with intrinsic resistances and temperature $[7,8]$.

On the other hand, the current-fed dual-active bridge (CFDAB) converter proposed in this paper reduced the current stresses in the voltage filters and, consequently, allowed the use of technologies with a longer lifetime and better efficiency, such as polyester or metalized capacitors [11-14].

Concerning the high-frequency transformer, the proposed modulations allowed the converter operation with reduced leakage inductances. This is interesting due to the possibility to use cores with higher relative magnetic permeability, such as nanocrystalline cores. Besides, the transformers used in $\mathrm{DAB}$ converters present higher volume and magnetic losses due to the energy storage in the leakage inductances.

The current-fed topologies suffered from high-voltage spikes and ringing across its switches, due to energy stored in the leakage inductance of the high-frequency transformer [7]. These recurrent problems in isolated dc-dc converters, especially in bidirectional applications, imply more stress, power losses, and electromagnetic interference in these converters. It may reduce efficiency and also compromise the safe operation of the semiconductors $[5,7,8,11,14]$. Reference [11] attenuates the overvoltage problems with a specific modulation, the addition of two auxiliary inductors and a voltage clamping cell.

In this paper, a modulation strategy was proposed to allow the converter operation without auxiliary circuits such as resonant cells, snubbers, or active-clamp circuits. Additionally, the proposal by [11] had 16 power stages, while in the current proposal, only eight stages were necessary for both operating modes of the converter.

References $[4,9,17]$ uses resonant cells for the operation of DAB converters. This characteristic allows soft switching operation. However, it increases current stresses in the converters and requires the use of frequency modulations. References [12,21] propose auxiliary circuits to reduce the semiconductors' overvoltage. These circuits add complexity and implementation costs.

Also, references [12,21] use PS modulation. In this type of strategy, linearized and small-signals' models were required for both operation modes of the converter (charge/discharge). References $[18,19]$ develop a linearized model, to represent the DAB converter. Therefore, modeling and control are complex. On the other hand, by applying the asymmetrical configuration and PWM strategy proposed in this paper, it was possible to obtain a simplified model to the CFDAB converter $[25,27,28]$. The experimental results showed that even with the use of simple controllers (PI and PID controllers) with fixed gains, it is possible to control the converter adequately.

\section{Conclusions}

This paper explored the application of an asymmetrical converter, the current-fed dual-active bridge (CFDAB), for the development, modeling, and control of an isolated bidirectional battery charger. In the presented approach, the performance of the CFDAB converter was analyzed independently for each operation mode, that is, charge and discharge modes. For both operation modes, PWM strategies were proposed to reduce the stress on the semiconductors and transformer without the 
use of auxiliary circuits, such as snubbers, resonant cells, or active-clamp elements. The proposed strategy also allowed obtaining simplified models, including a large-signals' model for the converter operating on charging mode. Details on the modeling, control system design, and experimental results to validate the proposal were presented.

Some advantages of the asymmetrical configuration were highlighted:

(1) Easy implementation and modeling;

(2) controlled by PWM strategies, which are known for simplicity;

(3) regulation of dc bus voltage with a constant level in both converter operation modes;

(4) independence of the transformer as an energy storage element;

(5) reduced semiconductors' stress due to the proposed modulation, applied to current-fed converters;

(6) operation without the use of auxiliary switching circuits; and

(7) application of the transformer with reduced leakage inductance and constant turns' ratio.

Author Contributions: Conceptualization, E.L.C. and R.C.; Formal analysis, E.L.C., L.H.M., E.G.C., C.M.d.O.S., and R.C.; Funding acquisition, J.P.d.C. and R.C.; Investigation, E.L.C. and L.H.M.; Methodology, E.L.C., C.M.d.O.S., and R.C.; Resources, J.P.d.C. and R.C.; Supervision, C.M.d.O.S., and R.C.; Validation, E.L.C. and L.H.M.; Writing-original draft, E.L.C. and L.H.M.; Writing-review \& editing, E.L.C., C.M.d.O.S., and R.C. All authors have read and agreed to the published version of the manuscript.

Funding: This research was funded by Research and Development Project PD 2866-0468/2017, granted by the Brazilian Electricity Regulatory Agency (ANEEL) and Companhia Paranaense de Energia (COPEL).

Acknowledgments: This study was financed in part by the Coordenação de Aperfeiçoamento de Pessoal de Nível Superior-Brasil (CAPES)-Finance Code 001. The authors would like to thank to the Research and Development Project PD 2866-0468/2017, granted by the Brazilian Electricity Regulatory Agency (ANEEL) and Companhia Paranaense de Energia (COPEL). The authors also thank to Financiadora de Estudos e Projetos (FINEP), Superintendência de Ciência, Tecnologia e Ensino Superior do Paraná (SETI), Conselho Nacional de Desenvolvimento Científico e Tecnológico (CNPq), Fundação Araucária, and Universidade Tecnológica Federal do Paraná (UTFPR) for additional funding.

Conflicts of Interest: The authors declare no conflict of interest.

\section{References}

1. Meneghetti, L.H.; Carvalho, E.L.; Carati, E.; Costa, J.P.; Stein, C.M.O.; Cardoso, R. Energy Storage System for Programmable Dispatch of Photovoltaic Generation. In Proceedings of the 21st European Conference on Power Electronics and Applications (EPE '19 ECCE Europe), Genova, Italy, 3-5 September 2019.

2. Nasir, M.; Jin, Z.; Khan, H.; Zaffar, N.; Vasquez, J.; Guerrero, J.M. A Decentralized Control Architecture Applied to DC Nanogrid Clusters for Rural Electrification in Developing Regions. IEEE Trans. Power Electron. 2019, 34, 1773-1785. [CrossRef]

3. Karthikeyan, V.; Gupta, R. Multiple-Input Configuration of Isolated Bidirectional DC-DC Converter for Power Flow Control in Combinational Battery Storage. IEEE Trans. Ind. Inform. 2018, 14, 2-11. [CrossRef]

4. Wang, C.; Zhang, S.; Wang, Y.; Chen, B.; Liu, J. A 5-kW Isolated High Voltage Conversion Ratio Bidirectional CLTC Resonant DC-DC Converter With Wide Gain Range and High Efficiency. IEEE Trans. Power Electron. 2019, 34, 340-355. [CrossRef]

5. Dung, N.; Chiu, H.; Lin, J.; Hsieh, Y.; Chen, H.; Zeng, B. Novel Modulation of Isolated Bidirectional DC-DC Converter for Energy Storage Systems. IEEE Trans. Power Electron. 2019, 34, 1266-1275. [CrossRef]

6. Rashid, M.H. Power Electronics Handbook: Devices, Circuits and Applications Handbook, 3th ed.; Elsevier: Oxford, UK, 2011.

7. Forouzesh, M.; Siwakoti, Y.; Gorji, S.; Blaabjerg, F.; Lehman, B. Step-Up DC-DC Converters: A Comprehensive Review of Voltage-Boosting Techniques, Topologies, and Applications. IEEE Trans. Power Electron. 2017, 32, 9143-9178. [CrossRef]

8. Pan, X.; Ghoshal, A.; Liu, Y.; Xu, Q.; Rathore, A.K. Hybrid-Modulation-Based Bidirectional Electrolytic Capacitor-Less Three-Phase Inverter for Fuel Cell Vehicles: Analysis, Design, and Experimental Results. IEEE Trans. Power Electron. 2018, 33, 4167-4180. [CrossRef] 
9. Hu, S.; Li, X.; Bhat, A. Operation of a Bidirectional Series-Resonant Converter with Minimized Tank Current and Wide ZVS Range. IEEE Trans. Power Electron. 2019, 34, 904-915. [CrossRef]

10. Akagi, H.; Tan, N.M.L.; Kinouchi, S.; Miyazaki, Y.; Koyama, M. Power-Loss Breakdown of a 750-V 100-kW 20-kHz Bidirectional Isolated DC-DC Converter Using SiC-MOSFET/SBD Dual Modules. IEEE Trans. Ind. Appl. 2015, 51, 420-428. [CrossRef]

11. Bal, S.; Yelaverthi, D.; Rathore, A.; Srinivasan, D. Improved Modulation Strategy Using Dual Phase Shift Modulation for Active Commutated Current-Fed Dual Active Bridge. IEEE Trans. Power Electron. 2018, 33, 7359-7375. [CrossRef]

12. Wu, T.; Yang, J.; Kuo, C.; Wu, Y. Soft-Switching Bidirectional Isolated Full-Bridge Converter with Active and Passive Snubbers. IEEE Trans. Ind. Electron. 2014, 61, 1368-1376. [CrossRef]

13. Zhao, B.; Song, Q.; Liu, W.; Su, Y. Overview of Dual-Active-Bridge Isolated Bidirectional DC-DC Converter for High-Frequency-Link Power-Conversion System. IEEE Trans. Power Electron. 2014, 29, 4091-4106. [CrossRef]

14. Carvalho, E.L.; Carati, E.; Costa, J.P.; Stein, C.M.; Cardoso, R. Development of an Isolated Bidirectional Converter Applied on Charging and Discharging of Batteries Banks. Brazilian Power Electron. J. 2018, 23, 349-359.

15. Cornea, O.; Andreescu, G.; Muntean, N.; Hulea, D. Bidirectional Power Flow Control in a DC Microgrid Through a Switched-Capacitor Cell Hybrid DC-DC Converter. IEEE Trans. Ind. Electron. 2017, 64, 3012-3022. [CrossRef]

16. Zhang, Y.; Gao, J.; Li, M. Sumner “Interleaved Switched-Capacitor Bidirectional DC-DC Converter With Wide Voltage-Gain Range for Energy Storage Systems". IEEE Trans. Power Electron. 2018, 33, 3852-3869. [CrossRef]

17. Dalala, Z.; Zahid, Z; Saadeh, O.; Lai, J. Modelling and Controller Design of a Bidirectional Resonant Converter Battery Charger. IEEE Access 2018, 6, 23338-23350. [CrossRef]

18. Qin, H.; Kimball, J.W. Generalized average modeling of dual active bridge DC-DC converter. IEEE Trans. Power Electron. 2011, 27, 2078-2084.

19. Sanders, S.R.; Noworolski, J.M.; Liu, X.Z.; Verghese, G.C. Generalized averaging method for power conversion circuits. IEEE Trans. Power Electron. 1991, 6, 251-259. [CrossRef]

20. Prassana, U.R.; Rathore, A.K. Extended Range ZVS Active-Clamped Current-Fed Full-Bridge Isolated DC/DC Converter for Fuel Cell Applications: Analysis, Design, and Experimental Results. IEEE Trans. Ind. Electron. 2013, 60, 2661-2672.

21. Imbertson, P.; Mohan, N. Asymmetrical Duty Cycle Permits Zero Switching Loss in PWM Circuits with No Conduction Loss Penalty. IEEE Trans. Ind. Appl. 1993, 29, 121-125. [CrossRef]

22. Li, C.; Zhang, Y.; Cao, Z.; Xu, D. Single-Phase Single-Stage Isolated ZCS Current-Fed Full-Bridge Converter for High-Power AC/DC Applications. IEEE Trans. Ind. Electron. 2017, 32, 6800-6812. [CrossRef]

23. Erikson, R.W.; Maksimovic, D. Fundamental of Power Electronics, 2nd ed.; Kluwer Academic/Plenum Publishers: Norwell, MA, USA, 2001.

24. Instruments, T. Phase-Shifted Full-Bridge, Zero-Voltage Transition Design Considerations; Application Report; Texas Instruments: Dallas, TX, USA, 2011.

25. Berndt, D. Electrochemical Energy Storage-Battery Technology Handbook, 2nd ed.; Marcel Dekker: New York, NY, USA, 2003.

26. Linden, D.; Reddy, T.B. Handbook of Batteries, 4th ed.; McGraw-Hill Professional: New York, NY, USA, 2011.

27. Carvalho, E.L.; Tambara, R.V.; Cardoso, R.; Michels, L. A Discrete-Time Robust Adaptive Controller Applied to a Bidirectional Isolated Converter. In Proceedings of the 11th Seminar on Power Electronics and Control (SEPOC 2018), Santa Maria, RS, Brazil, 2018. Available online: https://www.ufsm.br/laboratorios/inct/wpcontent/uploads/sites/737/2019/10/17-4.-Michels-Edivan-SEPOC-cont.pdf (accessed on 19 June 2020).

28. Carvalho, E.L.; Carati, E.; Costa, J.P.; Stein, C.M.O.; Cardoso, R. Small-Signal Modeling and Analysis of an Isolated Bidirectional Battery Charger. In Proceedings of the 13th IEEE/IAS International Conference on Industry Applications (INDUSCON 2018), São Paulo, Brazil, 12-14 November 2018.

(C) 2020 by the authors. Licensee MDPI, Basel, Switzerland. This article is an open access article distributed under the terms and conditions of the Creative Commons Attribution (CC BY) license (http://creativecommons.org/licenses/by/4.0/). 